\title{
THERMOGALVANIC EFFECTS ON THE CORROSION OF COPPER IN HEAVY BRINE LiBr SOLUTIONS
}

\author{
Fernández-Domene, R.M., Blasco-Tamarit, E., García-García, D.M., García-
} Antón, J. *

Ingeniería Electroquímica y Corrosión (IEC). Departamento de Ingeniería Química y Nuclear. ETSI Industriales. Universidad Politécnica de Valencia. P.O. Box 22012, E46071 Valencia. Spain.

Tel.34-96-387 76 30, Fax. 34-96-387 76 39, e-mail.jgarciaa@iqn.upv.es

Thermogalvanic corrosion of copper in heavy brine $\mathrm{LiBr}$ solutions has been investigated using a zero-resistance ammeter (ZRA). The temperature gradients between copper electrodes immersed in the same $\mathrm{LiBr}$ solution result in the formation of thermogalvanic cells with hot anodes, leading to high and sustained thermogalvanic currents. Copper loss rates, calculated using Faraday's law, substantially exceed $0.025 \mathrm{~mm}$ year $^{-1}$, a value regarded as the threshold of low corrosion rates. The effects of thermogalvanic coupling on the surface properties of the anode and the cathode have been analysed by means of electrochemical impedance spectroscopy (EIS). The results obtained in this analysis have been related to the process of copper electrodissolution in bromide media.

Keywords: A. Copper; B. EIS, polarisation; C. Anodic dissolution 


\section{INTRODUCTION}

In recent years, interest in absorption refrigeration technology has been growing because these systems use pairs of refrigerants and absorbents which do not deplete the ozone layer. Moreover, waste heat or solar energy can be used for their operation, thus helping to control global warming [1-3]. Lithium bromide ( $\mathrm{LiBr})$ solutions are widely used as refrigerants for absorption-type air-conditioning and industrial drying systems due to their good thermodynamic properties [3-6].

Copper has been used as the structural material of heat exchangers because of its excellent thermal conductivity and good corrosion resistance. Refrigeration systems based on absorption phenomena include copper and copper alloys in the system design [5, 7-9]. Since it is impossible to design heat exchangers where all the surfaces are isothermal, temperature differences on the same metal surface in contact with the same electrolyte solution can produce sufficient electrode potential differences to give rise to the formation of a thermogalvanic cell, which leads to thermogalvanic corrosion. Electrode potentials change with temperature, but temperature changes may also affect the kinetics of dissolution, in particular activation-controlled processes. Boden [10] reported that the electrode potential of copper electrodes in a $\mathrm{NaCl}$ solution became more anodic as temperature increased, creating a substantial thermogalvanic corrosion cell and enhancing corrosion rates. Bell et. al. [11] also obtained hot anodes when investigating thermogalvanic corrosion of copper pipes in a $3 \% \mathrm{NaCl}$ solution.

Bromide solutions are highly corrosive and attack the copper parts of the absorption system [7-9, 12-16]. Thus, the existence of zones with different temperatures inside the heat exchangers can aggravate the corrosion of copper in the $\mathrm{LiBr}$ solutions. 
Furthermore, the presence of $\mathrm{Cu}^{2+}$ in lithium bromide refrigerants resulting from the corrosion of copper equipment can cause the galvanic corrosion of ferrous parts in absorption systems [6].

This work studies the thermogalvanic behaviour of copper in heavy brine $\mathrm{LiBr}$ solutions imposing temperature gradients up to 75 degrees.

\section{EXPERIMENTAL PROCEDURE}

The working electrodes were copper cylindrical probes (99.9\% purity), $8 \mathrm{~mm}$ in diameter, with a total surface area of $0.5 \mathrm{~cm}^{2}$, covered with a 2-mm polytetrafluoroethylene (PTFE) coating. The electrodes were wet abraded using 500-, 1000- and 4000-grade silicon carbide ( $\mathrm{SiC}$ ) emery papers, and rinsed with distilled water. Aqueous solutions of $400 \mathrm{~g} / \mathrm{l}(4.61 \mathrm{M}), 700 \mathrm{~g} / \mathrm{l}(8.06 \mathrm{M})$ and $992 \mathrm{~g} / \mathrm{l}(11.42 \mathrm{M})$ LiBr were used.

The polarisation tests were determined using an Autolab PGSTAT302N potentiostat, in the three $\mathrm{LiBr}$ solutions mentioned above (400, 700 and $992 \mathrm{~g} / \mathrm{L} \mathrm{LiBr}$ ), at four different temperatures $\left(25,50,75\right.$ and $100^{\circ} \mathrm{C}$; the maximum temperature in the $400 \mathrm{~g} / \mathrm{l} \mathrm{LiBr}$ solution was $75^{\circ} \mathrm{C}$, since at $100^{\circ} \mathrm{C}$ the solution showed signs of boiling). The potentials of the working electrode were measured against a silver-silver chloride $(\mathrm{Ag} / \mathrm{AgCl} 3 \mathrm{M}$ $\mathrm{KCl})$ reference electrode. The auxiliary electrode was a platinum $(\mathrm{Pt})$ wire. Dissolved oxygen was removed from the $\mathrm{LiBr}$ solutions by bubbling $\mathrm{N}_{2}$ and the purging continued during the tests over the electrolyte. Polarisation tests began at a potential value of -50 $\mathrm{mV}_{\mathrm{Ag} / \mathrm{AgCl}}$ with respect to the open circuit potential and the potential was subsequently 
scanned anodically to $1 \mathrm{~V}_{\mathrm{Ag} / \mathrm{AgCl}}$ at a scanning rate of $0.5 \mathrm{mV} / \mathrm{s}$. Corrosion current densities $\left(i_{c o r r}\right)$ and corrosion potentials $\left(E_{c o r r}\right)$ were estimated from these curves and information about the general electrochemical behaviour of copper in the $\mathrm{LiBr}$ solutions at different temperatures was obtained.

The experimental arrangement used to study thermogalvanic corrosion is shown in Figure 1. The temperature difference between each half-cell is obtained by cooling directly one side and heating the other side using two thermostated baths. Electrolytic contact is achieved through a sintered glass membrane (porosity 3, with an internal resistance of 5-10 $\Omega$ ) fitted between the two compartments. The sintered glass membrane acts as a thermal and diffusional barrier between both half-cells, which prevents the hot and cold electrolytes from mixing and over which the stable temperature gradient occurs [17-22]. Thermogalvanic corrosion tests were performed at four different temperatures in the hot half-cell, namely $25,50,75$ and $100^{\circ} \mathrm{C}$ (when using the $400 \mathrm{~g} / \mathrm{l} \mathrm{LiBr}$ solution, the maximum temperature was $75^{\circ} \mathrm{C}$, since at $100^{\circ} \mathrm{C}$ the solution started boiling), while the cold half-cell was always at $25^{\circ} \mathrm{C}$. Measurements were carried out in an inert atmosphere by purging $\mathrm{N}_{2}$ over the electrolyte solution, which was deaerated previously for 20 minutes.

Thermogalvanic corrosion was studied by using the potentiostat as a Zero Resistance Ammeter (ZRA) (Figure 1). This procedure consists of connecting the cold and hot copper electrodes (WE1 and WE2, respectively) and recording current variations with time between them with the ZRA. Simultaneously, the potential of this couple is measured against a $\mathrm{Ag} / \mathrm{AgCl}$ reference electrode. The sign convention of the $\mathrm{ZRA}$ was that when the hot electrode (WE2) was anodic with respect to the cold electrode (WE1), 
the ZRA current was negative. ZRA current and potential data were recorded for 6 hours.

The EIS measurements were performed before and after the 6 hours of open circuit measurements (ZRA) at the open circuit potential value, in order to study the effects of the thermogalvanic couple on the electrolyte/metal interface. The voltage perturbation amplitude was $10 \mathrm{mV}$ in the frequency range of $100 \mathrm{kHz}$ to $10 \mathrm{mHz}$. The conditions of the EIS experiments were the same as those in the ZRA tests.

\section{RESULTS AND DISCUSSION}

\section{Potentiodynamic tests}

Potentiodynamic polarisation curves for copper in the $700 \mathrm{~g} / \mathrm{l} \mathrm{LiBr}$ solution at different temperatures $\left(25,50,75\right.$ and $\left.100^{\circ} \mathrm{C}\right)$ are presented in Figure 2. These curves are representative of polarisation curves for copper in heavy brine $\mathrm{LiBr}$ solutions, so curves for copper in the 400 and $992 \mathrm{~g} / \mathrm{l} \mathrm{LiBr}$ solutions are not presented here. Different anodic regions can be observed in the curves, as reported in the literature for copper in halide solutions [7, 12, 15, 23-32].

Region 1: apparent Tafel behaviour region.

Above the corrosion potential, $E_{c o r r}$, there is a region of active copper dissolution known as apparent Tafel behaviour region, where current density increases linearly with potential with a slope close to $60 \mathrm{mV} \mathrm{dec}{ }^{-1}[7,12,15,24-27,31]$. The anodic process ocurring in this region is the formation of soluble complexes in the form of $\mathrm{CuX}_{2}^{-}$ $\left(\mathrm{CuBr}_{2}{ }^{-}\right.$in bromide solutions) and can be attributed to a two-stage process: a charge 
transfer reaction at the electrode/electrolyte interface (eqs. 1a and 1b), and the diffusion of $\mathrm{CuBr}_{2}{ }^{-}$from the electrode surface towards the solution bulk (eq. 2), according to [7, 15, 23-26, 29-35]:

$$
\begin{gathered}
\mathrm{Cu}+\mathrm{Br}^{-} \Leftrightarrow \mathrm{CuBr}_{\text {ads }}+\mathrm{e}^{-} \\
\mathrm{CuBr}_{\text {ads }}+\mathrm{Br}^{-} \rightarrow\left(\mathrm{CuBr}_{2}^{-}\right)_{\mathrm{s}} \\
\left(\mathrm{CuBr}_{2}^{-}\right)_{\mathrm{s}} \rightarrow\left(\mathrm{CuBr}_{2}^{-}\right)_{\mathrm{e}}
\end{gathered}
$$

Where subscripts "ads", "s" and "e" indicate adsorbed species, electrode surface and electrolyte, respectively. The process of copper dissolution is therefore under mixed control, that is, it is controlled both by the electrodissolution process and the diffusion of complex $\mathrm{CuBr}_{2}^{-}$species from the outer Helmholtz plane $(O H P)$ towards the electrolyte through the diffusion layer [7, 23, 31, 36-39].

It can be observed in Figure 2 that current density values within this first region increase with increasing temperature. As it is widely known, charge and mass transfer rates increase with temperature; therefore, as temperature increases, the reactions described above are enhanced and current density values increase.

Region 2: maximum and limit current density region.

A current density maximum is observed beyond the apparent Tafel behaviour region. This current density peak and its subsequent decrease can be associated with the formation and growth of a porous and very insoluble layer of $\mathrm{CuX}(\mathrm{CuBr}$ in bromide 
solutions) on the copper surface [23-25, 31, 33, 34, 40-42], according to the following equations:

$$
\mathrm{Cu}+\mathrm{Br}^{-} \Leftrightarrow \mathrm{CuBr}+\mathrm{e}^{-}
$$

$$
\mathrm{Cu}+\mathrm{CuBr}_{2}^{-} \Leftrightarrow 2 \mathrm{CuBr}+\mathrm{e}^{-}
$$

The amount of $\mathrm{CuBr}$ increases with time, forming a layer that can make current density and, consequently, corrosion rate decrease, in spite of having no protective properties. The minimum value reached by current density after the peak indicates a maximum coverage of the surface by the $\mathrm{CuBr}$ layer [38]. As copper keeps reacting with bromide ions to form more $\mathrm{CuBr}$, the reaction rate decreases and equals the diffusion rate of bromide ions from the bulk solution to the electrode surface. After that, bromide diffusion becomes the rate-controlling step and current density reaches an approximately constant value (limit current density) within a potential range [12, 25, 33, $34,38,43]$. Because of the high current density values recorded in this second region, the corrosion product layer cannot be regarded as a true passive film [37].

It is noteworthy that as the temperature of the solution increases, the current density peak is less discernible, disappearing at $100^{\circ} \mathrm{C}$, where no current density minimum is observed. Moreover, current density values increase in this region with increasing temperatures. Therefore, it can be said that higher temperatures make the layer of $\mathrm{CuBr}$ weaker.

Region 3: high potential region. 
In the third region of polarisation curves, at potentials beyond the limit current density region, the $\mathrm{CuBr}$ layer undergoes further dissolution. Two competitive reactions have been suggested for this dissolution [24, 25, 34]:

$$
\mathrm{CuBr}+\mathrm{Br}^{-} \rightarrow \mathrm{CuBr}_{2}^{-}
$$

and

$$
\mathrm{CuBr} \rightarrow \mathrm{Cu}^{2+}+\mathrm{Br}^{-}+\mathrm{e}^{-}
$$

Since solubility of $\mathrm{CuBr}$ is very low, its dissolution occurs mainly due to complexation reaction, eq. (5). At the same time, the complex species $\mathrm{CuBr}_{2}^{-}$dissolves to give $\mathrm{Cu}^{2+}$ ions $[15,24,34]$ :

$$
\mathrm{CuBr}_{2}^{-} \rightarrow \mathrm{Cu}^{2+}+2 \mathrm{Br}^{-}+\mathrm{e}^{-}
$$

In addition to the dissolution of the $\mathrm{CuBr}$ layer due to bromide ions action, at these high potentials the formation of $\mathrm{Cu}$ (II) species from $\mathrm{CuBr}$ and $\mathrm{CuBr}_{2}^{-}$takes place $[15,24-26$, 38, 44]. Among the predominant $\mathrm{Cu}$ (II) compounds at high potential values, copper oxide, $\mathrm{CuO}$, is rather common $[15,40,43]$.

From the potentiodynamic polarisation curves, corrosion potentials $\left(E_{c o r r}\right)$, corrosion current densities $\left(i_{c o r r}\right)$ and anodic Tafel slopes $\left(\beta_{a}\right)$ are obtained (Table 1). It can be observed that $E_{\text {corr }}$ shifts towards more negative values as temperature increases, indicating that copper becomes more active and more prone to undergo corrosion at higher temperatures. Regarding $i_{c o r r}$, its value increases in general with temperature, since temperature favours the process of copper corrosion [43]. However, this tendency 
is not valid at $100^{\circ} \mathrm{C}$, since at this temperature $i_{\text {corr }}$ values are lower than at $75^{\circ} \mathrm{C}$ for the 700 and $992 \mathrm{~g} / \mathrm{l} \mathrm{LiBr}$ solutions. This effect is related to the structural modifications that take place during the process of copper dissolution: as the temperature of the solution increases from $75^{\circ} \mathrm{C}$ to $100^{\circ} \mathrm{C}$, the corrosion products formed on the electrode surface became more compact and less porous with temperature [43]. The value of the anodic Tafel slope, $\beta_{a}$, is approximately $60 \mathrm{mV}$, which is in accordance with the values obtained in bibliography for the apparent Tafel behaviour region [7, 12, 15, 24-27, 31].

\section{Thermogalvanic corrosion}

Open circuit measurements (ZRA)

Thermogalvanic corrosion between the cold and hot copper electrodes was evaluated by means of the ZRA technique, in the 400, 700 and $992 \mathrm{~g} / \mathrm{l} \mathrm{LiBr}$ solutions, imposing different temperature gradients (from 25 to $75^{\circ} \mathrm{C}$ in the $400 \mathrm{~g} / \mathrm{l} \mathrm{LiBr}$ solution and to $100^{\circ} \mathrm{C}$ in the rest of solutions). The mean values of thermogalvanic current densities $\left(i_{\text {thm }}\right)$ and thermogalvanic potentials $\left(E_{\text {thm }}\right)$, obtained for each hour of the test, are shown in Figures 3 and 4, respectively.

In the $400 \mathrm{~g} / \mathrm{l} \mathrm{LiBr}$ solution, the anodic member of the thermogalvanic pair is the hot copper electrode, since the $i_{\text {thm }}$ values become negative as the temperature in the hot half-cell increases (Figure 3a). Moreover, the higher the temperature of the hot copper electrode, the more severe the thermogalvanic corrosion, since $i_{t h m}$ increases (in absolute value). Thermogalvanic current density also increases (in absolute value) with coupling time, indicating that corrosion products are not able to protect the copper surface against dissolution. 
In the $700 \mathrm{~g} / \mathrm{LiBr}$ solution, the hot copper electrode is the anode of the thermogalvanic pair and the increase of temperature favours this anodic behaviour, since $i_{t h m}$ values increase with temperature (in absolute value) (Figure 3b) like in the $400 \mathrm{~g} / \mathrm{l} \mathrm{LiBr}$ solution. In the test performed at $25-50^{\circ} \mathrm{C}$, the cold electrode is the anode during the first 3 hours of immersion, although a polarity reversal occurs after that due to the effect of temperature, speeding up the dissolution of the hot copper electrode. In the $25-75^{\circ} \mathrm{C}$ and $25-100^{\circ} \mathrm{C}$ tests, the anodic behaviour of the hot electrode is much more marked. It is worth noting that in the $25-75^{\circ} \mathrm{C}$ test, $i_{\text {thm }}$ values are higher than at $25^{\circ}-100^{\circ} \mathrm{C}$ during the first 3 hours of coupling. As it has been mentioned above, at $100^{\circ} \mathrm{C}$ the corrosion product layer formed on the hot electrode surface can undergo structural modification, becoming more compact due to its dehydration favoured by a temperature increase [43]. At the end of the tests, $i_{\text {thm }}$ reaches more or less constant values, except at $25-100^{\circ} \mathrm{C}$, where thermogalvanic current density keeps increasing with time (values of $\left|i_{t h m}\right|$ higher than $\left.130 \mu \mathrm{A} \mathrm{cm}^{-2}\right)$.

In the $992 \mathrm{~g} / \mathrm{l} \mathrm{LiBr}$ solution, the hot copper electrode is again the anode of the thermogalvanic pair and this behaviour is favoured when the hot half-cell temperature increases (Figure 3c), the same as in the other $\mathrm{LiBr}$ solution.

In general, $E_{t h m}$ values decrease with increasing temperature in all the $\mathrm{LiBr}$ solutions (Figure 4). According to Ashworth and Boden [17] a decrease of the thermogalvanic potential with temperature is indicative of a hot anode. Besides, thermogalvanic potential values remain approximately constant during the six hours of coupling, 
indicating that no passive state is reached, since in passive systems the value of $E_{t h m}$ has been reported to decrease with immersion time [18].

It can be seen from Figure 3 that $i_{\text {thm }}$ values are rather high after the six hours of thermogalvanic coupling, especially in the tests performed at $25-75^{\circ} \mathrm{C}$ and $25-100^{\circ} \mathrm{C}$. These values are expected to increase (in absolute value) with thermogalvanic coupling time or, at best, to reach a steady state, which evidences an active corrosion process, as opposed to the decrease of $i_{\text {thm }}$ observed for passive systems [18]. This fact indicates that thermogalvanic corrosion of copper in $\mathrm{LiBr}$ solutions becomes more serious with coupling time, which could result in early system failure. Besides, thermogalvanic potential values are located in the region of apparent Tafel behaviour (Figure 2), where copper dissolution takes place according to eqs. (1) and (2), confirming the existence of an active corrosion process during thermogalvanic coupling.

Severity of thermogalvanic action

From Figure 3, thermogalvanic current density $\left(i_{t h m}\right)$ values of copper can be converted to an equivalent corrosion penetration rate using Faraday's equation. Thus, the rate of copper loss can be determined by:

$$
\frac{d L}{d t} \equiv m=\frac{i_{t h m} M}{n F \rho}
$$

where $m$ is the instantaneous corrosion rate of copper, $i_{t h m}$ is thermogalvanic current density (obtained at the end of the sixth hour of thermogalvanic coupling), $M$ is the atomic weight of copper $\left(63.55 \mathrm{~g} \mathrm{~mol}^{-1}\right), n$ is the number of equivalent exchanged electrons ( 1 according to eq. (1a)), $F$ is Faraday's constant $\left(96485.34 \mathrm{C} \mathrm{mol}^{-1}\right.$ ) and $\rho$ is 
copper density $\left(8.94 \mathrm{~g} \mathrm{~cm}^{-3}\right)$. Table 2 shows the estimations of corrosion rates for copper in the three $\mathrm{LiBr}$ solutions at the different imposed temperature gradients.

It can be seen in Table 2 that corrosion rates of copper are significantly higher than $0.025 \mathrm{~mm} \mathrm{year}^{-1}$ (which is generally regarded as the threshold of low corrosion rates and is related to passive systems) [45], especially in the $700 \mathrm{~g} / \mathrm{l} \mathrm{LiBr}$ solutions at $25^{\circ} \mathrm{C}$ $75^{\circ} \mathrm{C}$ and $25^{\circ} \mathrm{C}-100^{\circ} \mathrm{C}$. Moreover, it can be noticed from Figure 3 that in most cases, $i_{\text {thm }}$ values tend to increase (in absolute value) with time even after 6 hours of immersion, without reaching a steady state. Thermogalvanic corrosion will remain as long as temperature differences exist in the system, which is the operating situation in heat exchangers, leading to their rapid deterioration. Hence, unlike in passive systems [18], thermogalvanic corrosion of copper in heavy brine $\mathrm{LiBr}$ solutions is severe and must be taken into account when designing heat exchangers in absorption plants.

\section{Thermogalvanic potentials and Seebeck coefficient}

The thermogalvanic potential, $E_{t h}$, is the electromotive force of a non-isothermal or thermogalvanic cell, and is the result of four main effects [18, 46-48]: (a) electrode temperature, (b) thermal liquid junction potential (TLJP), (c) metallic thermocouple and (d) thermal diffusion gradient or Soret effect. In practical systems, (c) and (d) are often very small [46-50]. In neutral and alkaline solutions, (b) may be small [47]; moreover, $T L J P$ can be effectively reduced to a small value by using the sintered glass membrane as a separator between hot and cold half-cells. Thus, the major contribution to the thermogalvanic potential is the difference in metal/solution Galvani potentials $[18,47]$. 
The thermogalvanic potential can be expressed as follows:

$$
E_{t h}=\frac{\partial E_{t h}}{\partial T} \cdot \Delta T+E_{0}=E^{\prime} \cdot \Delta T+E_{0}
$$

where $\mathrm{E}_{0}$ is the cell potential when there is no temperature gradient $(\Delta T=0)$. By analogy with thermoelectric phenomena, the gradient $\partial E_{t h} / \partial T=E$ ' is defined as the Seebeck coefficient $[18,51-53]$ and can be calculated from the slope of the linear representation $E_{t h}$ vs $\Delta T$. Seebeck coefficients provide the sensitivity of the thermogalvanic cell emf (thermogalvanic potential) to a variation of the temperature gradient present in the system. Thus, the higher the value of the Seebeck coefficient (in absolute value), the smaller the variation in temperature gradient required to generate large potential differences between the electrodes, and the more prone the metal to undergo thermogalvanic corrosion.

Figure 5 shows the results of the experiments that evaluate the concentration dependence of the Seebeck coefficient for copper in the three $\mathrm{LiBr}$ solutions under study. The graphs show typical experimental measurements of Seebeck coefficients in thermogalvanic cells, since a linear relation is observed for all concentrations $[18,19$, $48,50,54,55]$. Seebeck coefficients are negative for all the $\mathrm{LiBr}$ solutions, meaning that the electric potential of the cold electrode is positive with respect to the hot one. Therefore, electrons diffuse from the hot zone to the cold zone and the hot electrode is the anode of the thermogalvanic pair $[19,50,52]$, in agreement with the ZRA results for $i_{\text {thm }}$. 
The similar slopes in Figure 5 indicate that the Seebeck coefficient does not depend on the $\mathrm{LiBr}$ concentration and remains approximately constant. This fact can be explained in terms of $\mathrm{LiBr}$ concentrations, higher than $31 \mathrm{wt} . \%$. Other authors $[18,48,50]$ have found that in several solutions $\left(\mathrm{CuSO}_{4}\right.$ and $\left.\mathrm{LiBr}\right)$ whose concentrations were higher than 6.4 wt.\%, the value of Seebeck coefficient did not depend on the electrolyte concentration.

\section{EIS measurements}

EIS spectra

By way of illustration, Figure 6 shows the evolution of the impedance response of the cold and hot copper electrodes immersed in $700 \mathrm{~g} / \mathrm{l} \mathrm{LiBr}$ solution before and after the thermogalvanic coupling (BTC and ATC, respectively), in the form of Nyquist and Bode-phase plots. Three time constants can be discerned in the Bode plots, as it has been reported in numerous studies concerning copper behaviour against corrosion in halide solutions [56-59]. At high frequencies, the phase angle drops to 0 degrees as frequency increases; this response is typical of resistive behaviour and corresponds to the electrolyte resistance. At intermediate frequencies, the Bode plots show two phase maxima close to 45 degrees, which is characteristic of diffusion processes $[29,58]$. In the low frequency region, phase angle values do not decrease with decreasing frequencies, but remain constant or even increase slightly.

In the Nyquist plots, a semicircle in the high frequency region is followed by a diffusion tail in the intermediate and low frequency region, characteristic of Warburg impedance 
behaviour related to diffusion processes (enlarged plots in Figure 6). This implies that copper corrosion in $\mathrm{LiBr}$ solutions can be diffusion controlled, which is in accordance with reactions (1) and (2) taking place within the region of apparent Tafel behaviour (Figure 2). This mass transfer process is the diffusion of the soluble complex $\mathrm{CuBr}_{2}^{-}$ framed in the process of copper active corrosion.

The first time constant observed at high-intermediate frequencies $(\approx 1 \mathrm{kHz})$ in Figure 6 corresponds to a maximum phase angle and is related to charge transfer processes. Before thermogalvanic coupling, e cold electrodes have higher phase angles in this region than the hot electrodes. After thermogalvanic coupling, both electrodes reach higher phase angle values than before coupling, evidencing that the resistance to charge transfer is somewhat increased after 6 hours of thermogalvanic coupling. The second time constant observed at low-intermediate frequencies $(\approx 1-10 \mathrm{~Hz})$ in the Bode-phase diagrams of Figure 6 is related to the corrosion products formed on the copper surface. In general, the anode of the thermogalvanic pair (the hot electrode) has higher phase angle values than the cathode (the cold electrode), indicating a slightly better capacitive behaviour of the hot electrode after coupling. Nevertheless, these phase angle values are rather low, and the layer of corrosion products cannot be regarded as an insulator, since it offers little protection to the electrode. It can be noticed from the Nyquist plots in Figure 6 that before thermogalvanic coupling the cold electrode has the best resistive behaviour. In general, the resistive behaviour of the hot electrode (the anode of the pair) improves after thermogalvanic coupling (with the exception of the $25-100^{\circ} \mathrm{C}$ test), whereas the resistive behaviour of the cold electrode (the cathode of the pair) gets worse with coupling time. 


\section{Electrical equivalent circuit}

The EIS spectra of the cold and hot copper electrodes immersed in the three $\mathrm{LiBr}$ solutions before and after thermogalvanic coupling have been analysed by fitting the data to the electrical equivalent circuit shown in Figure 7, which has been used elsewhere to model the copper/electrolyte interface in the presence of chlorides $[27,30$, $36,56,58,60-62]$. In this equivalent circuit, $R_{S}$ represents the electrolyte resistance. $C P E_{1}$ is the electrical double layer capacitance which behaves as a non-ideal capacitor. This double layer capacitance is connected in parallel to the Faradaic impedace, which is composed of a charge transfer resistance $\left(R_{1}\right)$ corresponding to the $\mathrm{CuBr}$ and $\mathrm{CuBr}_{2}{ }^{-}$ formation reactions, eqs. (1a) and (1b), the capacitance and resistance of the layer of corrosion products formed on the copper surface $\left(C P E_{2}\right.$ and $R_{2}$, respectively) and a finite Warburg impedance or OFLD element (Open Boundary Finite Length Diffusion Model). The OFLD element is used to take into account diffusion processes with finite diffusion layer, assuming that the Nernst diffusion layer thickness is comparable to the distance travelled by diffusing species. In the present case, diffusion occurs due to the partial obstruction of mass transfer by the corrosion product layer formed on the electrode surface (mainly $\mathrm{CuBr}$, eq. (1a)). Hence, as it has been explained above, the copper corrosion mechanism in $\mathrm{LiBr}$ solutions is not only charge-transfer controlled but also mass-transfer controlled due to the diffusion of the soluble complex $\mathrm{CuBr}_{2}{ }^{-}$.

A CPE (Constant Phase Element) represents a deviation from the ideal behaviour of a capacitor and can be used to replace a conventional capacitance. CPEs are used to model surface heterogeneities, roughness effects and variations in properties and/or 
composition of surface layers [26, 60, 63, 64]. The impedance of a constant-phase element is defined as:

$$
Q=Z_{C P E}=\left[C(j \omega)^{\alpha}\right]^{-1}
$$

where $\alpha$ is the CPE power and accounts for deviation from ideality of capacitive behaviour. Thus, for a perfectly polished surface without heterogeneities, the CPE power yields a value of $\alpha=1$ and represents an ideal capacitor. For real electrodes, $\alpha<$ 1. When there are diffusion processes, $\alpha$ is close to 0.5 .

The equation of the OFLD element used to model $\mathrm{CuBr}_{2}^{-}$diffusion through the corrosion product layer is:

$$
Z_{W}(O F L D)=\frac{\tanh (B \cdot \sqrt{j \omega})}{Y_{0} \cdot \sqrt{j \omega}}
$$

where $B=l /(D)^{1 / 2}, D$ is the diffusion coefficient, $l$ is the diffusion layer thickness, $Y_{0}=$ $\left(\sigma(2)^{1 / 2}\right)^{-1}$ and $\sigma$ is the Warburg coefficient. Since the Warburg coefficient is inversely proportional to the admittance $Y_{0}$, the higher this coefficient the higher the mass-transfer resistance. Therefore, from the parameters $B$ and $Y_{0}$, the diffusion layer thickness $l$, which can be regarded as equivalent to the corrosion products layer thickness, and the Warburg coefficient can be calculated. 
The diffusion coefficient of the $\mathrm{CuBr}_{2}^{-}$complex has been calculated from the diffusion coefficient of $\mathrm{Br}^{-}$in the different $\mathrm{LiBr}$ solutions at the different temperatures, supposing that $D_{B r^{-}} \approx 4 D_{\mathrm{CuBr} 5_{2}^{-}}$as Deslouis et. at. did for $\mathrm{CuCl}_{2}^{-}$[65]. The values of $D_{B r-}$ in the different $\mathrm{LiBr}$ solutions at the different temperatures have been calculated from data for $\mathrm{LiBr}$ solutions at $25^{\circ} \mathrm{C}$ [66], using the Stokes-Einstein equation for diffusivity. This equation is derived from continuum fluid mechanics and classical thermodynamics for the motion of large spherical particles in a liquid. The Stokes-Einstein equation is [67]:

$$
D_{A B}=\frac{k T}{6 \pi r_{A} \mu_{B}}
$$

where A refers to the solute and B refers to the solvent, $D$ is the diffusion coefficient, $k$ is Boltzman Constant $\left(1.38 \cdot 10^{-23} \mathrm{~J} / \mathrm{K}\right), \mu$ is the dynamic viscosity of the pure solvent (in $\mathrm{Pa} \cdot \mathrm{s}), T$ is the temperature and $r$ is the solute molecule radius. Since $k$ and $r_{A}$ do not vary with temperature, an approximate dependence of the diffusion coefficient on temperature in liquids can be found by using the following expression derived from Stokes-Einstein equation:

$$
\frac{D_{T 1}}{D_{T 2}}=\frac{T_{1}}{T_{2}} \frac{\mu_{T 2}}{\mu_{T 1}}
$$

Viscosity values of pure water at different temperatures have been determined from bibliographic data [66]. Diffusivities of $\mathrm{CuBr}_{2}^{-}$in the $\mathrm{LiBr}$ solutions at different temperatures are in the range of $5 \cdot 10^{-6}-3 \cdot 10^{-5} \mathrm{~cm} \mathrm{~s}^{-2}$. These values are of the same order of magnitude as the diffusion coefficient for $\mathrm{CuCl}_{2}{ }^{-}$species in $1 \mathrm{M} \mathrm{HCl}$ at $25^{\circ} \mathrm{C}$ [62]. 
The stability of the system is crucial for the validity of EIS measurements. In order to validate the EIS data and examine the system with respect to the linearity, causality and stability, the Kramers-Kronig transforms have been applied to the experimental impedance data by transforming the real axis into the imaginary axis and the imaginary axis into the real axis and then comparing the transformed quantities with the respective experimental data. Only those experimental data satisfying the four physical conditions of causality, stability, linearity, and finiteness, can be used to describe the properties of the systems in terms of LST (Linear Systems Theory) and hence linear models. Figure 8 has been obtained for the test $25-75^{\circ} \mathrm{C}$ in the $992 \mathrm{~g} / \mathrm{l} \mathrm{LiBr}$ solution, where the system seems not to be stable (see $E_{t h}$ values in Figure $4 \mathbf{c}$ ). This figure shows good agreement between the set of the impedance data and corresponding $\mathrm{K}-\mathrm{K}$ transforms, demonstrating that the system satisfies the constraints of LST and is therefore stable.

The equivalent circuit parameters calculated for the cold and hot copper electrodes before and after thermogalvanic coupling (BTC and ATC, respectively) in the different LiBr solutions are presented in Tables 3-5. The chi-square values, $\chi^{2}$, are on the order of $10^{-3}-10^{-4}$, which indicates the goodness of fit of the equivalent circuit used in this work. The values of the charge transfer resistance, $R_{l}$, decrease with increasing temperatures and increase with coupling time, meaning that temperature favours charge transfer on the electrodes surface, while immersion time makes charge transfer somewhat difficult. Nevertheless, electrode polarity seems to have no noticeable effect on this parameter, since the tendency of the anode and cathode of the thermogalvanic pair is similar. It can also be noticed that $R_{l}$ values are rather small and close to the electrolyte resistance, $R_{S}$, implying that the charge transfer process of copper electrodissolution takes place spontaneously and actively. The values of the double layer capacitance, $C_{l}$, are 
consistent with observations for double layer capacities at the metal/electrolyte interface, typically in the range of 10 to $40 \mu \mathrm{F} / \mathrm{cm}^{2}[68,69]$. $C_{l}$ values do not show a clear tendency with temperature, coupling time or electrode polarity. CPE power values for the first capacitance, $\alpha_{1}$, are slightly lower than unity, indicating that the behaviour of the electrical double layer corresponds to a capacitor with some imperfections.

The second time constant, represented by $\left(R_{2} / / C P E_{2}\right)$ in Figure 7 has been related to the surface layer formed by corrosion products (mainly $\mathrm{CuBr}$ according to eqs. (1a) and (3)). The resistance of this layer, $R_{2}$, is higher than the charge transfer resistance, $R_{l}$, taking values from 60 to $500 \Omega \mathrm{cm}^{2}$. However, $R_{2}$ values are rather low compared with those obtained for passive films formed on austenitic stainless steels in the same heavy brine $\mathrm{LiBr}$ solutions, whose order of magnitude is hundreds of $\mathrm{k} \Omega \mathrm{cm}^{2}$ [18]. As shown in Tables 3-5, $R_{2}$ tend to decrease with increasing temperature before thermogalvanic coupling, indicating a worse corrosion behaviour of copper at higher temperatures. By contrast, with coupling time, $R_{2}$ tends to increase in the anode of the pair (the hot electrode) and tends to decrease in the cathode (the cold electrode). This fact can be related to the thickness of the surface layer, since this layer tends to grow as copper electrodissolution progresses in the anode, whereas it grows to a lesser extent on the cathode surface where it can be further electrochemically reduced during thermogalvanic coupling. The polarisation resistance, $R_{P}$, has been calculated as $R_{1}+R_{2}$, and represents the total resistance of charge transfer processes, whereas diffusion is modelled by the Warburg component. Since the main contribution to $R_{p}$ is the layer of corrosion products, its tendency with temperature and coupling time is the same as $R_{2}$. The values of the surface layer capacitance, $C_{2}$, are very high, of the order of $10^{-3}-10^{-2}$ $\mathrm{F} \mathrm{cm}^{-2}$, indicating that the layer has no insulating properties. Moreover, $\alpha_{2}$ values 
deviate greatly from 1 , indicating severe surface heterogeneity and a very porous nature. Values of $\alpha_{2}$ close to 0.5 evidence the presence of a diffusion process, supporting the use of a finite-length Warburg element (OFLD) to model mass transfer phenomena. Hence, the relatively low values of $R_{2}$ and the high values of $C_{2}$ verify the high defectiveness and the low protective properties of the $\mathrm{CuBr}$ layer.

The corrosion product layer thickness, $\delta$, and the Warburg coefficient, $\sigma$, have been calculated from the parameters of the OFLD model. In general, thickness increases with thermogalvanic coupling time in the anode of the pair (hot electrode) and decreases in the cathode (cold electrode). These results are in accordance with the $R_{2}$ values and suggest that the formation of a $\mathrm{CuBr}$ layer through the active electrodissolution of copper, eqs. (1a) and (3), takes place predominantly on the anode surface, while reduction processes take place primarily on the cathode surface. In some cases, the thickness of the surface layer also increases in the cathode after thermogalvanic coupling. The polarity of the electrodes is determined by the predominant behaviour as anode or as cathode; hence, the cathode of the pair could undergo some degree of dissolution, which is reflected by the formation of a corrosion product layer. As for the Warburg coefficient, $\sigma$, its value decreases with temperature, indicating a decrease in mass transfer resistance at higher temperatures, except for the $992 \mathrm{~g} / \mathrm{l} \mathrm{LiBr}$ solution. No effect of electrode polarity on the Warburg coefficient can be noticed from Tables 3-5. 


\section{Conclusions}

Potentiodynamic polarisation curves for copper in heavy brine $\mathrm{LiBr}$ solutions exhibit different anodic regions: (1) apparent Tafel behaviour region, where the formation of $\mathrm{CuBr}$ and $\mathrm{CuBr}_{2}^{-}$species occurs by a two-stage process which is controlled both by the electrodissolution process and the diffusion of complex $\mathrm{CuBr}_{2}^{-}$species; (2) : maximum and limit current density region, where the formation and growth of a porous and very insoluble $\mathrm{CuBr}$ layer takes place; and (3) high potential region, where the $\mathrm{CuBr}$ layer dissolves and $\mathrm{Cu}(\mathrm{II})$ species such as $\mathrm{CuO}$ are formed.

From the potentiodynamic polarisation curves, it can be said that temperature negatively affects the corrosion behaviour of copper in heavy brine LiBr solutions, since $E_{\text {corr }}$ shifts towards more negative values and current density values increase with increasing temperature.

The anodic member of the thermogalvanic pair is the hot copper electrode in the three $\mathrm{LiBr}$ solutions under study. Moreover, temperature enhances the anodic behaviour of the hot copper electrodes. Rates of copper loss are by far higher than $0.025 \mathrm{~mm}^{\mathrm{year}}{ }^{-1}$, which is regarded as the threshold of low corrosion rates. Moreover, thermogalvanic current density values also increase (in absolute value) with coupling time, without reaching a steady state, leading to rapid deterioration of process equipment. Thus, it can be said that thermogalvanic corrosion of copper in heavy brine $\mathrm{LiBr}$ solutions is severe and must be taken into account when designing heat exchangers in absorption plants. 
Seebeck coefficients are negative for all the $\mathrm{LiBr}$ solutions, meaning that the electrons diffuse from the hot zone to the cold zone and the hot electrode is the anode of the thermogalvanic pair, in agreement with the ZRA results for $i_{t h m}$.

The EIS plots show three time constants, related to charge transfer on the electrode surface, the properties of the $\mathrm{CuBr}$ layer and the diffusion of the soluble $\mathrm{CuBr}_{2}^{-}$ complex, respectively. The charge transfer process responsible for the formation of $\mathrm{CuBr}$ and $\mathrm{CuBr}_{2}^{-}$is enhanced by temperature, although it is not affected by electrode polarity. The thickness $\left(\delta_{\mathrm{CuBr}}\right)$ and the resistance $\left(R_{2}\right)$ of the corrosion product layer increase on the anode surface after thermogalvanic coupling, whereas $R_{2}$ and $\delta_{\mathrm{CuBr}}$ decrease on the cathode surface.

\section{ACKNOWLEDGEMENTS}

We wish express our gratitude to the Ministerio de Ciencia e Innovación (Project CTQ2009-07518), for the economical support of this research and to Dr. M. Asunción Jaime for her translation assistance.

\section{REFERENCES}

[1] S. C. Kaushik, A. Arora, Energy and exergy analysis of single effect and series flow double effect water-lithium bromide absorption refrigeration systems, Int. J. Refrig. 32 (2009) 1247-1258. 
[2] O. Kaynakli, M. Kilic, Theoretical study on the effect of operating conditions on performance of absorption refrigeration system, Energ. Convers. Manage. 48 (2007) 599-607.

[3] R. D. Misra, P. K. Sahoo, A. Gupta, Thermoeconomic evaluation and optimization of a double-effect $\mathrm{H} 2 \mathrm{O} / \mathrm{LiBr}$ vapour-absorption refrigeration system, Int. J. Refrig. 28 (2005) 331-343.

[4] P. Srikhirin, S. Aphornratana, S. Chungpaibulpatana, A review of absorption refrigeration technologies, Renew. Sust. Energ. Rev. 5 (2001) 343-372.

[5] G. A. Florides, S. A. Kalogirou, S. A. Tassou, L. C. Wrobel, Design and construction of a LiBr-water absorption machine, Energ. Convers. Manage. 44 (2003) 2483-2508.

[6] H. Cheng, $\mathrm{Cu}$ (II) Removal from lithium bromide refrigerant by chemical precipitation and electrocoagulation, Sep. Purif. Technol. 52 (2006) 191-195.

[7] M. Itagaki, Y. Hirata, K. Watanabe, Anodic dissolution and disproportional reaction of copper in bromide solution investigated by channel flow electrode, Corros. Sci. 45 (2003) 1023-1036.

[8] A. Igual-Muñoz, J. García-Antón, J. L. Guiñón, V. Pérez-Herranz, Galvanic Studies of Copper Coupled to Alloy 33 and Titanium in Lithium Bromide Solutions, CORROSION 58 (2002) 995-1003.

[9] A. Igual-Muñoz, J. García-Antón, J. L. Guiñón, V. Pérez-Herranz, Comparison of inorganic inhibitors of copper, nickel and copper-nickels in aqueous lithium bromide solution, Electrochim. Acta 50 (2004) 957-966. 
[10] P. J. Boden, Corrosion of $\mathrm{Cu}$ and $\mathrm{Cu}$-base alloys under conditions of boiling heat transfer--I. Corrosion of Cu, Corros. Sci. 11 (1971) 353-362.

[11] G. E. C. Bell, M. J. Schiff, D. F. Wilson, Field Observations and Laboratory Investigations of Thermogalvanic Corrosion of Copper Tubing, Corrosion 97, Paper No. 568. 1997. Houston, TX, NACE International.

[12] T. Aben, D. Tromans, Anodic Polarization Behavior of Copper in Aqueous Bromide and Bromide/Benzotriazole Solutions, J. Electrochem. Soc. 142 (1995) 398-404.

[13] D. Itzhak, T. Greenberg, Galvanic Corrosion of a Copper Alloy in Lithium Bromide Heavy Brine Environments, CORROSION 55 (1999) 795-799.

[14] A. Igual-Muñoz, J. García-Antón, J. L. Guiñón, V. Pérez-Herranz, Galvanic Study of Zinc and Copper in Lithium Bromide Slutions at Different Temperatures, CORROSION 57 (2001) 516-522.

[15] M. J. Muñoz-Portero, J. García-Antón, J. L. Guiñón, V. Pérez-Herranz, Anodic Polarization Behavior of Copper in Concentrated Aqueous Lithium Bromide Solutions and Comparison with Pourbaix Diagrams, CORROSION 61 (2005) 464-472.

[16] R. Sánchez-Tovar, M. T. Montañés, J. García-Antón, The effect of temperature on the galvanic corrosion of the copper/AISI 304 pair in $\mathrm{LiBr}$ solutions under hydrodynamic conditions, Corros. Sci. 52 (2010) 722-733. 
[17] V. Ashworth, P. J. Boden, The thermogalvanic corrosion of mild steel in alkaline solution I: Actively dissolving electrodes, Corros. Sci. 14 (1974) 183197.

[18] R. M. Fernández-Domene, E. Blasco-Tamarit, D. M. García-García, J. GarcíaAntón, Thermogalvanic corrosion of Alloy 31 in different heavy brine $\mathrm{LiBr}$ solutions, Corros. Sci. 55 (2012) 40-53.

[19] J. W. Tester. Evaluation of Thermogalvanic Cells for the Conversion of Heat to Electricity, MIT Energy Lab, Technical Report MIT-EL, 92-007 (1992).

[20] R. Hu, B. A. Cola, N. Haram, J. N. Barisci, S. Lee, S. Stoughton, G. Wallace, C. Too, M. Thomas, A. Gestos, M. E. d. Cruz, J. P. Ferraris, A. A. Zakhidov, R. H. Baughman, Harvesting Waste Thermal Energy Using a CarbonNanotube-Based Thermo-Electrochemical Cell, Nano Lett. 10 (2010) 838-846.

[21] J. C. Verhoef, E. Barendrecht, Electrochemical behaviour of iodide at a rotating platinum disk electrode in methanol, Electrochim. Acta 23 (1978) 433-438.

[22] V. S. Bagotsky, Fundamentals of Electrochemistry, 2nd ed., John Wiley \& Sons, Hoboken, NJ, 2006, Ch. 5.

[23] D. Tromans, J. C. Silva, Behavior of Copper in Acidic Sulfate Solution: Comparison with Acidic Chloride, CORROSION 53 (1997) 171-178.

[24] H. P. Lee, K. Nobe, Kinetics and Mechanisms of $\mathrm{Cu}$ Electrodissolution in Chloride Media, J. Electrochem. Soc. 133 (1986) 2035-2043. 
[25] F. K. Crundwell, The anodic dissolution of $90 \%$ copper-10\% nickel alloy in hydrochloric acid solutions, Electrochim. Acta 36 (1991) 2135-2141.

[26] A. V. Benedeti, P. T. A. Sumodjo, K. Nobe, P. L. Cabot, W. G. Proud, Electrochemical studies of copper, copper-aluminium and copper-aluminiumsilver alloys: Impedance results in 0.5M NaCl, Electrochim. Acta 40 (1995) 2657-2668.

[27] H. Y. Ma, C. Yang, S. H. Chen, Y. L. Jiao, S. X. Huang, D. G. Li, J. L. Luo, Electrochemical investigation of dynamic interfacial processes at 1octadecanethiol-modified copper electrodes in halide-containing solutions, Electrochim. Acta 48 (2003) 4277-4289.

[28] E. S. Sherif, R. M. Erasmus, J. D. Comins, Effects of 3-amino-1,2,4-triazole on the inhibition of copper corrosion in acidic chloride solutions, J. Colloid Interf. Sci. 311 (2007) 144-151.

[29] D. Q. Zhang, L. X. Gao, G. D. Zhou, Inhibition of copper corrosion by bis-(1benzotriazolymethylene)-(2,5-thiadiazoly)-disulfide in chloride media, Appl. Surf. Sci. 225 (2004) 287-293.

[30] K. F. Khaled, Studies of the corrosion inhibition of copper in sodium chloride solutions using chemical and electrochemical measurements, Mat. Chem. Phys. 125 (2011) 427-433.

[31] Y. G. Chun, S. I. Pyun, C. H. Kim, Effect of aluminium content on the anodic behaviour of copper-aluminium alloys in $3.5 \mathrm{wt} \% \mathrm{NaCl}$ solution, Mater. Lett. 20 (1994) 265-270. 
[32] W. Li, L. Hu, S. Zhang, B. Hou, Effects of two fungicides on the corrosion resistance of copper in $3.5 \% \mathrm{NaCl}$ solution under various conditions, Corros. Sci. 53 (2011) 735-745.

[33] L. Brossard, Potentiodynamic Investigation of Copper in the Presence of Bromide Ions, J. Electrochem. Soc. 131 (1984) 1847-1849.

[34] J. Y. Josefowicz, L. Xie, G. C. Farrington, Observation of Intermediate $\mathrm{CuCl}$ Species during the Anodic Dissolution of Cu Using Atomic Force Microscopy, J. Phys. Chem. 97 (1993) 11995-11998.

[35] O. E. Barcia, O. R. Mattos, N. Pebere, B. Tribollet, Mass-Transport Study for the Electrodissolution of Copper in 1M Hydrochloric Acid Solution by Impedance, J. Electrochem. Soc. 140 (1993) 2825-2832.

[36] E. M. Sherif, S. M. Park, Inhibition of copper corrosion in acidic pickling solutions by N-phenyl-1,4-phenylenediamine, Electrochim. Acta 51 (2006) $4665-4673$

[37] H. Otmacic, E. Stupnisek-Lisac, Copper corrosion inhibitors in near neutral media, Electrochim. Acta 48 (2003) 985-991.

[38] G. Kear, B. D. Barker, F. C. Walsh, Electrochemical corrosion of unalloyed copper in chloride media--a critical review, Corros. Sci. 46 (2004) 109-135.

[39] R. Vera, F. Bastidas, M. Villarroel, A. Oliva, A. Molinari, D. Ramírez, R. del Río, Corrosion inhibition of copper in chloride media by 1,5-bis(4dithiocarboxylate-1-dodecyl-5-hydroxy-3-methylpyrazolyl)pentane, Corros. Sci. 50 (2008) 729-736. 
[40] S. M. Milic, M. M. Antonijevic, Some aspects of copper corrosion in presence of benzotriazole and chloride ions, Corros. Sci. 51 (2009) 28-34.

[41] H. Otmacic Curkovic, E. Stupnisek-Lisac, H. Takenouti, The influence of pH value on the efficiency of imidazole based corrosion inhibitors of copper, Corros. Sci. 52 (2010) 398-405.

[42] G. Kear, B. D. Barker, K. Stokes, F. C. Walsh, Electrochemical Corrosion Behaviour of 90-10 Cu-Ni Alloy in Chloride-Based Electrolytes, J. Appl. Electrochem. 34 (2004) 659-669.

[43] M. J. Muñoz-Portero, J. García-Antón, J. L. Guiñón, V. Pérez-Herranz, Corrosion of Copper in Aqueous Lithium Bromide Concentrated Solutions by Immersion Testing, CORROSION 62 (2006) 1018-1027.

[44] M. M. Antonijevic, S. M. Milic, M. B. Petrovic, Films formed on copper surface in chloride media in the presence of azoles, Corros. Sci. 51 (2009) $1228-1237$

[45] J. R. Scully and R. G. Kelly in: S. D. Cramer (Ed.), B. S. Covino, Jr. (Ed.), Corrosion: Fundamentals, Testing and Protection, Vol. 13, ASM Handbook, ASM International, 2003.

[46] L. B. Kriksunov. Thermogalvanic Effects in Corrosion in Supercritical Water, Corrosion 98, NACE, Houston, TX, 1998, paper no. 418.

[47] P.J. Boden in: L.L. Shreir (Ed.), R.A. Jarman (Ed.), G.T. Burstein (Ed.), Corrosion and Corrosion Control, vol. 1, 3rd ed., Butterworth-Heinemann, Oxford, 1994. 
[48] K. Szabó, E. Földesi, Study of the $\mathrm{CuCu}(\mathrm{NO} 3) 2 \cdot \mathrm{H} 2 \mathrm{OCu}$ electrochemical thermocouple at low temperatures, J. Electroanal. Chem. 452 (1998) 107-111.

[49] B. E. Conway, D. P. Wilkinson, Non-isothermal cell potentials and evaluation of entropies of ions and of activation for single electrode processes in nonaqueous media, Electrochim. Acta 38 (1993) 997-1013.

[50] U. B. Holeschovsky, Analysis of flooded flow fuel cells and thermogalvanic generators, Ph.D. Thesis, Massachusetts Institute of Technology (1994).

[51] D.D. Pollock in: D.M. Rowe (Ed.), CRC Handbook of Thermoelectrics, 1st ed., CRC Press, Boca Ratón, FL, 1995, Ch. 2.

[52] S.O. Kasap, Thermoelectric effects in metals: thermocouples, An e-booklet, 2001, http://materials.usask.ca/samples/Thermoelectric-Seebeck.pdf (22-032011).

[53] J. Newman, Thermoelectric Effects in Electrochemical Systems, Ind. Eng. Chem. Res. 34 (1995) 3208-3216.

[54] D. S. Carr, C. F. Bonilla, Thermogalvanic Potentials II. Nickel in Neutral Sulfate Solution, J. Electrochem. Soc. 99 (1952) 475-482.

[55] R. Schneebaum, B. R. Sundheim, Thermoelectric Properties of the Silver Nitrate+Sodium Nitrate System, Discuss. Faraday Soc. 32 (1961) 197-202.

[56] E. S. Sherif, R. M. Erasmus, J. D. Comins, Inhibition of copper corrosion in acidic chloride pickling solutions by 5-(3-aminophenyl)-tetrazole as a corrosion inhibitor, Corros. Sci. 50 (2008) 3439-3445. 
[57] Y. Van Ingelgem, A. Hubin, J. Vereecken, Investigation of the first stages of the localized corrosion of pure copper combining EIS, FE-SEM and FE-AES, Electrochim. Acta 52 (2007) 7642-7650.

[58] R. M. El-Sherif, K. M. Ismail, W. A. Badawy, Effect of $\mathrm{Zn}$ and $\mathrm{Pb}$ as alloying elements on the electrochemical behavior of brass in $\mathrm{NaCl}$ solutions, Electrochim. Acta 49 (2004) 5139-5150.

[59] Y. Van Ingelgem, E. Tourwé, J. Vereecken, A. Hubin. Application of multisine impedance spectroscopy, FE-AES and FE-SEM to study the early stages of copper corrosion, Electrochim. Acta 53 (2008) 7523-7530.

[60] K. M. Ismail, A. M. Fathi, W. A. Badawy, Electrochemical behavior of copper-nickel alloys in acidic chloride solutions, Corros. Sci. 48 (2006) 19121925.

[61] W. A. Badawy, K. M. Ismail, A. M. Fathi, Effect of Ni content on the corrosion behavior of $\mathrm{Cu}-\mathrm{Ni}$ alloys in neutral chloride solutions, Electrochim. Acta 50 (2005) 3603-3608.

[62] J. P. Diard, J. M. Le Canut, B. Le Gorrec, C. Montella, Copper electrodissolution in $1 \mathrm{M} \mathrm{HCl}$ at low current densities II. Electrochemical impedance spectroscopy study, Electrochim. Acta 43 (1998) 2485-2501.

[63] A. Nagiub, F. Mansfeld, Evaluation of corrosion inhibition of brass in chloride media using EIS and ENA, Corros. Sci. 43 (2001) 2147-2171. 
[64] T. Kosec, D. K. Merl, I. Milosev, Impedance and XPS study of benzotriazole films formed on copper, copper-zinc alloys and zinc in chloride solution, Corros. Sci. 50 (2008) 1987-1997.

[65] C. Deslouis, O. R. Mattos, M. M. Musiani, B. Tribollet, Comments on mechanisms of copper electrodissolution in chloride media, Electrochim. Acta 38 (1993) 2781-2783.

[66] D.R.Lide (Ed.), CRC Handbook of Chemistry and Physics, CRC Press, Boca Raton, FL, 2008.

[67] R. B. Bird, W. E. Stewart, and E. N. Lightfoot, Transport Phenomena, John Wiley \& Sons, New York, NY, 2002.

[68] A. J. Bard and L. R. Faulkner, Electrochemical Methods: Fundamentals and Applications, John Wiley \& Sons, New York, NY, 2001.

[69] M. E. Orazem and B. Tribollet, Electrochemical Impedance Spectroscopy, John Wiley \& Sons, Hoboken, NJ, 2008. 


\section{$\underline{\text { Tables captions }}$}

Table 1.

Values of $E_{\text {corr }}$ and $i_{\text {corr }}$ for copper in 400, 700 and $992 \mathrm{~g} / \mathrm{l} \mathrm{LiBr}$ solutions at 25, 50, 75 and $100^{\circ} \mathrm{C}$.

Table 2.

Rates of copper loss in 400, 700 and $992 \mathrm{~g} / \mathrm{LiBr}$ solutions at different temperatures, in presence of thermogalvanic coupling (by $i_{t h m}$ ).

Table 3 .

Calculated equivalent circuit parameters for cold and hot copper electrodes before and after the thermogalvanic coupling (BTC and ATC, respectively) in the $400 \mathrm{~g} / \mathrm{l} \mathrm{LiBr}$ solution.

Table 4

Calculated equivalent circuit parameters for cold and hot copper electrodes before and after the thermogalvanic coupling (BTC and ATC, respectively) in the $700 \mathrm{~g} / \mathrm{l} \mathrm{LiBr}$ solution.

Table 5.

Calculated equivalent circuit parameters for cold and hot copper electrodes before and after the thermogalvanic coupling (BTC and ATC, respectively) in the $992 \mathrm{~g} / \mathrm{LiBr}$ solution. 


\section{$\underline{\text { Figures captions }}$}

Fig. 1.

Electrochemical cell used for thermogalvanic corrosion tests.

Fig. 2.

Potentiodynamic polarisation curves for copper in the $700 \mathrm{~g} / \mathrm{LiBr}$ solution at $25,50,75$ and $100^{\circ} \mathrm{C}$.

Fig. 3.

Mean values of thermogalvanic current density registered between the pair cold copper - hot copper during each hour of the test at different imposed temperature gradients in the (a) $400 \mathrm{~g} \mathrm{l}^{-1} \mathrm{LiBr}$, (b) $700 \mathrm{~g}$ $\mathrm{l}^{-1} \mathrm{LiBr}$ and (c) $992 \mathrm{~g} \mathrm{l}^{-1} \mathrm{LiBr}$ solutions.

Fig. 4.

Mean values of thermogalvanic potential registered between the pair cold copper - hot copper during each hour of the test at different imposed temperature gradients in the (a) $400 \mathrm{~g} \mathrm{l}^{-1} \mathrm{LiBr}$, (b) $700 \mathrm{~g} \mathrm{l}^{-1} \mathrm{LiBr}$ and (c) $992 \mathrm{~g} \mathrm{l}^{-1} \mathrm{LiBr}$ solutions.

Fig. 5.

Thermogalvanic potential $\left(E_{t h}\right)$ vs. temperature gradient $(\Delta T)$ for the three LiBr solutions under study.

Fig. 6.

Nyquist and Bode-phase plots for the pair cold copper - hot copper at OCP in the $700 \mathrm{~g} \mathrm{l}^{-1} \mathrm{LiBr}$ solution at the temperature gradients of (a) $25^{\circ} \mathrm{C}-25^{\circ} \mathrm{C}$, (b) $25^{\circ} \mathrm{C}-50^{\circ} \mathrm{C}$, (c) $25^{\circ} \mathrm{C}-75^{\circ} \mathrm{C}$ and (d) $25^{\circ} \mathrm{C}-100^{\circ} \mathrm{C}$, before and after the thermogalvanic coupling (BTC and ATC, respectively).

Fig. 7.

Representation of the equivalent circuit proposed for the interpretation of EIS spectra of copper in the LiBr solutions under study.

Fig. 8 .

Kramers-Kronig transforms of EIS data for the hot copper electrode after thermogalvanic coupling in the $992 \mathrm{~g} / \mathrm{l} \mathrm{LiBr}$ solution. 


\begin{tabular}{|c|c|c|c|c|}
\hline $\mathrm{C}_{\mathrm{LiBr}} / \mathrm{g} \mathrm{l}^{-1}$ & $\mathrm{~T} /{ }^{\circ} \mathrm{C}$ & $E_{\text {corr }} \mathrm{vs}(\mathrm{Ag} / \mathrm{AgCl}) / \mathrm{mV}$ & $i_{\text {corr }} / \mu \mathrm{A} \mathrm{cm}^{-2}$ & $\beta_{a} / \mathrm{mV}$ \\
\hline 400 & 25 & $-339 \pm 21$ & $10.36 \pm 2.62$ & 61.5 \\
\hline & 50 & $-345 \pm 5$ & $19.63 \pm 3.12$ & 60.6 \\
\hline & 75 & $-450 \pm 16$ & $37.16 \pm 0.35$ & 61.7 \\
\hline & & & & \\
\hline 700 & 25 & $-399 \pm 6$ & $21.02 \pm 7.85$ & 63.3 \\
\hline & 50 & $-407 \pm 4$ & $28.87 \pm 6.33$ & 62.4 \\
\hline & 75 & $-424 \pm 11$ & $50.78 \pm 3.31$ & 62.8 \\
\hline & 100 & $-492 \pm 9$ & $36.16 \pm 4.22$ & 61.5 \\
\hline & & & & \\
\hline 992 & 25 & $-481 \pm 11$ & $13.36 \pm 3.29$ & 61.9 \\
\hline & 50 & $-463 \pm 17$ & $29.84 \pm 0.20$ & 54.9 \\
\hline & 75 & $-490 \pm 5$ & $36.71 \pm 2.10$ & 59.6 \\
\hline & 100 & $-519 \pm 9$ & $31.01 \pm 2.07$ & 61.2 \\
\hline
\end{tabular}




\begin{tabular}{|c|c|c|c|}
\hline $\mathrm{C}_{\mathrm{LiBr}} / \mathrm{g}^{-1}$ & Test & $\left|i_{\text {thm }}\right| / \mu \mathrm{A} \mathrm{cm}^{-2}$ & $m_{\text {ithm }} / \mathrm{mm} \mathrm{year}^{-1}$ \\
\hline 400 & $25^{\circ} \mathrm{C}-50^{\circ} \mathrm{C}$ & 13.05 & 0.303 \\
\hline & $25^{\circ} \mathrm{C}-75^{\circ} \mathrm{C}$ & 23.89 & 0.555 \\
\hline & & & \\
\hline 700 & $25^{\circ} \mathrm{C}-50^{\circ} \mathrm{C}$ & 11.62 & 0.270 \\
\hline & $25^{\circ} \mathrm{C}-75^{\circ} \mathrm{C}$ & 55.98 & 1.301 \\
\hline & $25^{\circ} \mathrm{C}-100^{\circ} \mathrm{C}$ & 139.26 & 3.236 \\
\hline & & & \\
\hline 992 & $25^{\circ} \mathrm{C}-50^{\circ} \mathrm{C}$ & 3.74 & 0.087 \\
\hline & $25^{\circ} \mathrm{C}-75^{\circ} \mathrm{C}$ & 8.91 & 0.207 \\
\hline & $25^{\circ} \mathrm{C}-100^{\circ} \mathrm{C}$ & 20.49 & 0.476 \\
\hline
\end{tabular}




\begin{tabular}{|c|c|c|c|c|c|c|c|c|c|c|c|}
\hline Electrode & $R_{S} / \Omega \mathrm{cm}^{2}$ & $R_{I} / \Omega \mathrm{cm}^{2}$ & $C_{1} / \mathrm{F} \mathrm{cm}^{-2}$ & $\alpha_{1}$ & $R_{2} / \Omega \mathrm{cm}^{2}$ & $R_{P} / \Omega \mathrm{cm}^{2}$ & $C_{2} / \mathrm{F} \mathrm{cm}^{-2}$ & $\alpha_{2}$ & $\delta / \mu \mathrm{m}$ & $\sigma / \Omega \mathrm{cm}^{2} \mathrm{~s}^{-1 / 2}$ & $\chi^{2}$ \\
\hline $25^{\circ} \mathrm{C}-25^{\circ} \mathrm{C}$ & & & & & & & & & & \\
\hline Cold and hot (BTC) & 1.13 & 22.48 & $2.34 \cdot 10^{-5}$ & 0.91 & 527.91 & 550.39 & 0.003 & 0.49 & 124 & 192 & $5.8 \cdot 10^{-4}$ \\
\hline Cold (ATC) & 1.20 & 13.01 & $1.38 \cdot 10^{-5}$ & 0.85 & 252.25 & 265.26 & 0.001 & 0.56 & 134 & 70 & $7.0 \cdot 10^{-4}$ \\
\hline Hot (ATC) & 1.10 & 13.22 & $2.15 \cdot 10^{-5}$ & 0.87 & 589.95 & 603.17 & 0.003 & 0.52 & 98 & 139 & $7.0 \cdot 10^{-4}$ \\
\hline & & & & & & & & & & & \\
\hline $25^{\circ} \mathrm{C}-50^{\circ} \mathrm{C}$ & & & & & & & & & & & \\
\hline Cold (BTC) & 1.13 & 22.48 & $2.34 \cdot 10^{-5}$ & 0.91 & 527.91 & 550.39 & 0.003 & 0.49 & 124 & 192 & $5.8 \cdot 10^{-4}$ \\
\hline Hot (BTC) & 0.90 & 2.18 & $1.62 \cdot 10^{-5}$ & 0.93 & 155.82 & 158.00 & 0.004 & 0.40 & 112 & 17 & $9.9 \cdot 10^{-4}$ \\
\hline Cold (ATC) & 1.13 & 21.94 & $3.54 \cdot 10^{-5}$ & 0.88 & 577.87 & 599.81 & 0.002 & 0.47 & 89 & 479 & $2.5 \cdot 10^{-3}$ \\
\hline Hot (ATC) & 0.97 & 17.75 & $2.67 \cdot 10^{-5}$ & 0.82 & 168.90 & 186.65 & $3 \cdot 10^{-4}$ & 0.50 & 255 & 67 & $2.7 \cdot 10^{-3}$ \\
\hline & & & & & & & & & & & \\
\hline $25^{\circ} \mathrm{C}-75^{\circ} \mathrm{C}$ & & & & & & & & & & \\
\hline Cold (BTC) & 1.13 & 22.48 & $2.34 \cdot 10^{-5}$ & 0.91 & 527.91 & 550.39 & 0.003 & 0.49 & 124 & 192 & $5.8 \cdot 10^{-4}$ \\
\hline Hot (BTC) & 0.68 & 0.76 & $2.69 \cdot 10^{-5}$ & 0.98 & 249.50 & 250.26 & 0.067 & 0.44 & 111 & 140 & $1.1 \cdot 10^{-3}$ \\
\hline Cold (ATC) & 1.09 & 32.48 & $2.79 \cdot 10^{-5}$ & 0.91 & 397.95 & 430.43 & 0.001 & 0.51 & 113 & 64 & $8.7 \cdot 10^{-4}$ \\
\hline Hot (ATC) & 0.67 & 2.18 & $1.96 \cdot 10^{-5}$ & 0.98 & 168.40 & 170.58 & 0.038 & 0.41 & 134 & 191 & $5.9 \cdot 10^{-4}$ \\
\hline
\end{tabular}




\begin{tabular}{|c|c|c|c|c|c|c|c|c|c|c|c|}
\hline Electrode & $R_{S} / \Omega \mathrm{cm}^{2}$ & $R_{l} / \Omega \mathrm{cm}^{2}$ & $C_{1} / \mathrm{F} \mathrm{cm}^{-2}$ & $\alpha_{1}$ & $R_{2} / \Omega \mathrm{cm}^{2}$ & $R_{P} / \Omega \mathrm{cm}^{2}$ & $C_{2} / \mathrm{F} \mathrm{cm}^{-2}$ & $\alpha_{2}$ & $\delta / \mu \mathrm{m}^{\circ}$ & $\sigma / \Omega \mathrm{cm}^{2} \mathrm{~s}^{-1 / 2}$ & $\chi^{2}$ \\
\hline $25^{\circ} C-25^{\circ} \mathrm{C}$ & & & & & & & & & & \\
\hline Cold and hot (BTC) & 1.32 & 7.14 & $2.64 \cdot 10^{-5}$ & 0.88 & 506.87 & 514.01 & 0.024 & 0.48 & 139 & 145 & $6.3 \cdot 10^{-4}$ \\
\hline Cold (ATC) & 1.42 & 16.49 & $2.33 \cdot 10^{-5}$ & 0.91 & 346.50 & 362.99 & 0.003 & 0.47 & 147 & 46 & $8.2 \cdot 10^{-4}$ \\
\hline Hot (ATC) & 1.32 & 24.37 & $2.50 \cdot 10^{-5}$ & 0.89 & 265.20 & 289.57 & 0.002 & 0.50 & 173 & 29 & $8.5 \cdot 10^{-4}$ \\
\hline & & & & & & & & & & & \\
\hline $25^{\circ} C-50^{\circ} C$ & & & & & & & & & & & \\
\hline Cold (BTC) & 1.32 & 7.14 & $2.64 \cdot 10^{-5}$ & 0.88 & 506.87 & 514.01 & 0.024 & 0.48 & 139 & 145 & $6.3 \cdot 10^{-4}$ \\
\hline Hot (BTC) & 0.99 & 0.41 & $2.18 \cdot 10^{-5}$ & 0.98 & 67.82 & 68.23 & 0.028 & 0.42 & 171 & 42 & $6.1 \cdot 10^{-4}$ \\
\hline Cold (ATC) & 1.23 & 19.32 & $2.69 \cdot 10^{-5}$ & 0.87 & 180.00 & 199.32 & 0.001 & 0.53 & 202 & 30 & $1.1 \cdot 10^{-3}$ \\
\hline Hot (ATC) & 0.98 & 8.36 & $2.10 \cdot 10^{-5}$ & 0.94 & 449.00 & 457.36 & 0.069 & 0.39 & 127 & 21 & $4.3 \cdot 10^{-4}$ \\
\hline & & & & & & & & & & \\
\hline $25^{\circ} C-75^{\circ} C$ & & & & & & & & & & \\
\hline Cold (BTC) & 1.32 & 7.14 & $2.64 \cdot 10^{-5}$ & 0.88 & 506.87 & 514.01 & 0.024 & 0.48 & 139 & 145 & $6.3 \cdot 10^{-4}$ \\
\hline Hot (BTC) & 0.71 & 0.59 & $2.68 \cdot 10^{-5}$ & 0.95 & 86.77 & 87.36 & 0.074 & 0.44 & 143 & 90 & $8.5 \cdot 10^{-4}$ \\
\hline Cold (ATC) & 1.33 & 20.13 & $4.38 \cdot 10^{-5}$ & 0.78 & 152.50 & 172.63 & 0.002 & 0.49 & 152 & 26 & $5.9 \cdot 10^{-4}$ \\
\hline Hot (ATC) & 0.73 & 2.18 & $2.17 \cdot 10^{-5}$ & 0.97 & 114.69 & 116.87 & 0.035 & 0.41 & 155 & 213 & $8.9 \cdot 10^{-4}$ \\
\hline & & & & & & & & & & \\
\hline $25^{\circ} C-100^{\circ} C$ & & & & & & & & & & \\
\hline Cold (BTC) & 1.32 & 7.14 & $2.64 \cdot 10^{-5}$ & 0.88 & 506.87 & 514.01 & 0.024 & 0.48 & 139 & 145 & $6.3 \cdot 10^{-4}$ \\
\hline Hot (BTC) & 0.59 & 0.94 & $2.94 \cdot 10^{-5}$ & 0.96 & 204.94 & 205.88 & 0.098 & 0.48 & 113 & 123 & $7.6 \cdot 10^{-4}$ \\
\hline Cold (ATC) & 1.21 & 7.58 & $2.47 \cdot 10^{-5}$ & 0.95 & 108.60 & 116.18 & 0.002 & 0.45 & 142 & 23 & $7.7 \cdot 10^{-4}$ \\
\hline Hot (ATC) & 0.61 & 1.14 & $2.59 \cdot 10^{-5}$ & 0.99 & 63.01 & 64.15 & 0.025 & 0.45 & 137 & 143 & $1.9 \cdot 10^{-3}$ \\
\hline
\end{tabular}




\begin{tabular}{|c|c|c|c|c|c|c|c|c|c|c|c|}
\hline Electrode & $R_{S} / \Omega \mathrm{cm}^{2}$ & $R_{l} / \Omega \mathrm{cm}^{2}$ & $C_{1} / \mathrm{F} \mathrm{cm}^{-2}$ & $\alpha_{1}$ & $R_{2} / \Omega \mathrm{cm}^{2}$ & $R_{P} / \Omega \mathrm{cm}^{2}$ & $C_{2} / \mathrm{F} \mathrm{cm}^{-2}$ & $\alpha_{2}$ & $\delta / \mu \mathrm{m}^{\circ}$ & $\sigma / \Omega \mathrm{cm}^{2} \mathrm{~s}^{-1 / 2}$ & $\chi^{2}$ \\
\hline $25^{\circ} C-25^{\circ} \mathrm{C}$ & & & & & & & & & & \\
\hline Cold and hot (BTC) & 1.69 & 11.62 & $3.41 \cdot 10^{-5}$ & 0.85 & 319.94 & 331.56 & 0.002 & 0.44 & 228 & 93 & $6.8 \cdot 10^{-4}$ \\
\hline Cold (ATC) & 1.29 & 3.50 & $1.95 \cdot 10^{-5}$ & 0.68 & 102.50 & 106.00 & 0.002 & 0.47 & 266 & 53 & $1.2 \cdot 10^{-3}$ \\
\hline Hot (ATC) & 1.20 & 8.41 & $2.07 \cdot 10^{-5}$ & 0.83 & 133.00 & 141.41 & 0.005 & 0.41 & 133 & 149 & $4.9 \cdot 10^{-3}$ \\
\hline & & & & & & & & & & & \\
\hline $25^{\circ} C-50^{\circ} C$ & & & & & & & & & & & \\
\hline Cold (BTC) & 1.69 & 11.62 & $3.41 \cdot 10^{-5}$ & 0.85 & 319.94 & 331.56 & 0.002 & 0.44 & 228 & 93 & $6.8 \cdot 10^{-4}$ \\
\hline Hot (BTC) & 1.17 & 4.92 & $4.20 \cdot 10^{-5}$ & 0.89 & 79.29 & 84.21 & 0.078 & 0.41 & 130 & 619 & $3.9 \cdot 10^{-4}$ \\
\hline Cold (ATC) & 1.68 & 61.07 & $4.87 \cdot 10^{-5}$ & 0.83 & 94.78 & 155.85 & 0.003 & 0.46 & 181 & 309 & $3.7 \cdot 10^{-3}$ \\
\hline Hot (ATC) & 1.32 & 8.14 & $2.10 \cdot 10^{-5}$ & 0.91 & 266.45 & 274.59 & 0.041 & 0.44 & 391 & 527 & $7.6 \cdot 10^{-4}$ \\
\hline & & & & & & & & & & \\
\hline $25^{\circ} C-75^{\circ} C$ & & & & & & & & & & \\
\hline Cold (BTC) & 1.69 & 11.62 & $3.41 \cdot 10^{-5}$ & 0.85 & 319.94 & 331.56 & 0.002 & 0.44 & 228 & 93 & $6.8 \cdot 10^{-4}$ \\
\hline Hot (BTC) & 0.92 & 0.64 & $2.35 \cdot 10^{-5}$ & 0.98 & 127.14 & 127.78 & 0.225 & 0.43 & 126 & 620 & $9.7 \cdot 10^{-4}$ \\
\hline Cold (ATC) & 1.61 & 21.88 & $3.64 \cdot 10^{-5}$ & 0.85 & 205.00 & 226.88 & 0.009 & 0.45 & 151 & 228 & $3.2 \cdot 10^{-3}$ \\
\hline Hot (ATC) & 0.90 & 1.28 & $2.19 \cdot 10^{-5}$ & 0.94 & 152.70 & 153.98 & 0.051 & 0.43 & 384 & 308 & $1.8 \cdot 10^{-3}$ \\
\hline & & & & & & & & & & \\
\hline $25^{\circ} C-100^{\circ} C$ & & & & & & & & & & \\
\hline Cold (BTC) & 1.69 & 11.62 & $3.41 \cdot 10^{-5}$ & 0.85 & 319.94 & 331.56 & 0.002 & 0.44 & 228 & 93 & $6.8 \cdot 10^{-4}$ \\
\hline Hot (BTC) & 0.66 & 1.49 & $3.13 \cdot 10^{-5}$ & 0.96 & 58.36 & 59.85 & 0.011 & 0.46 & 260 & 507 & $6.6 \cdot 10^{-4}$ \\
\hline Cold (ATC) & 1.56 & 21.69 & $4.49 \cdot 10^{-5}$ & 0.88 & 56.09 & 77.78 & 0.001 & 0.53 & 139 & 262 & $9.5 \cdot 10^{-3}$ \\
\hline Hot (ATC) & 0.69 & 3.74 & $3.30 \cdot 10^{-5}$ & 0.96 & 83.75 & 87.49 & 0.008 & 0.47 & 361 & 553 & $8.6 \cdot 10^{-4}$ \\
\hline
\end{tabular}




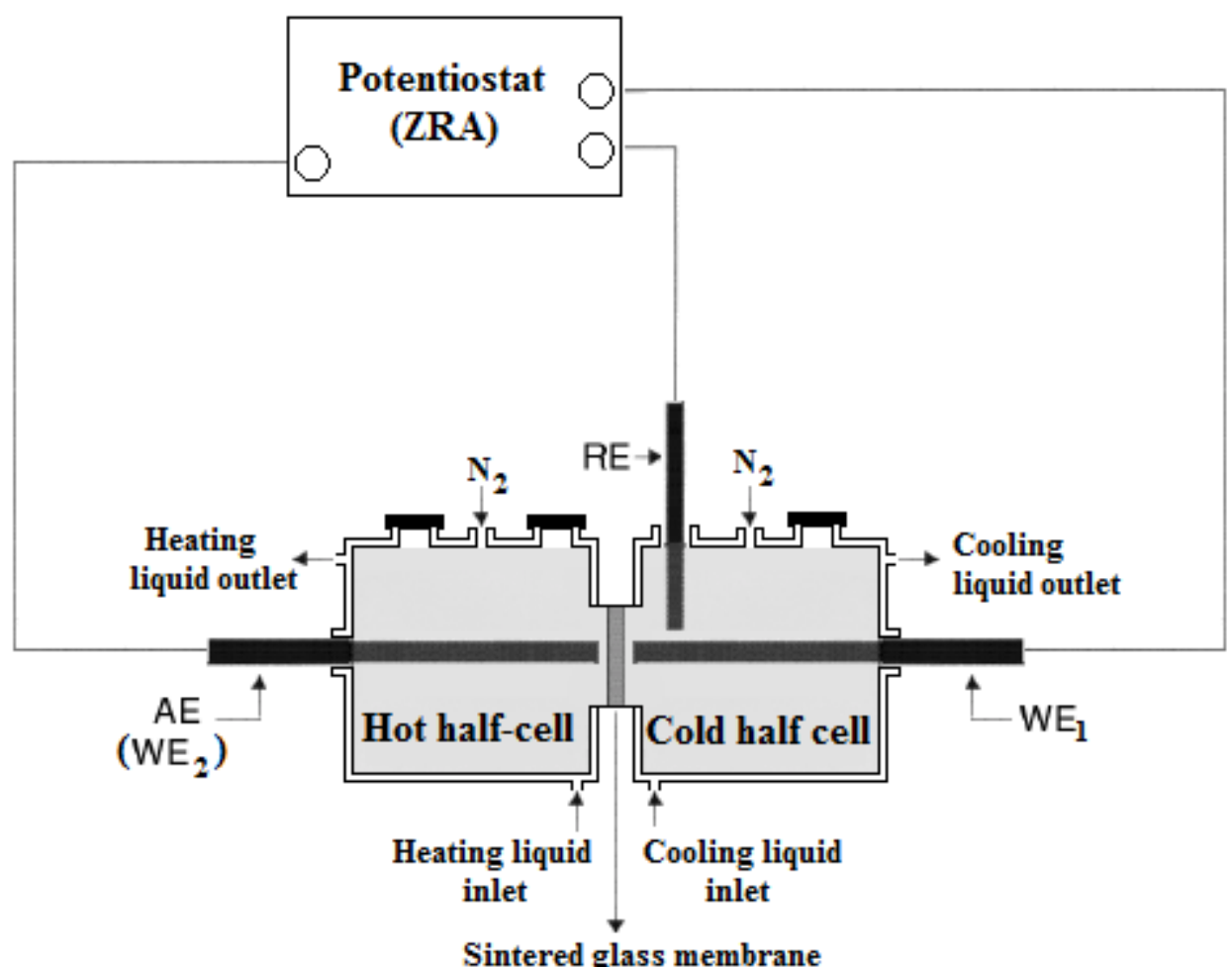

Sintered glass membrane 
Figure 2

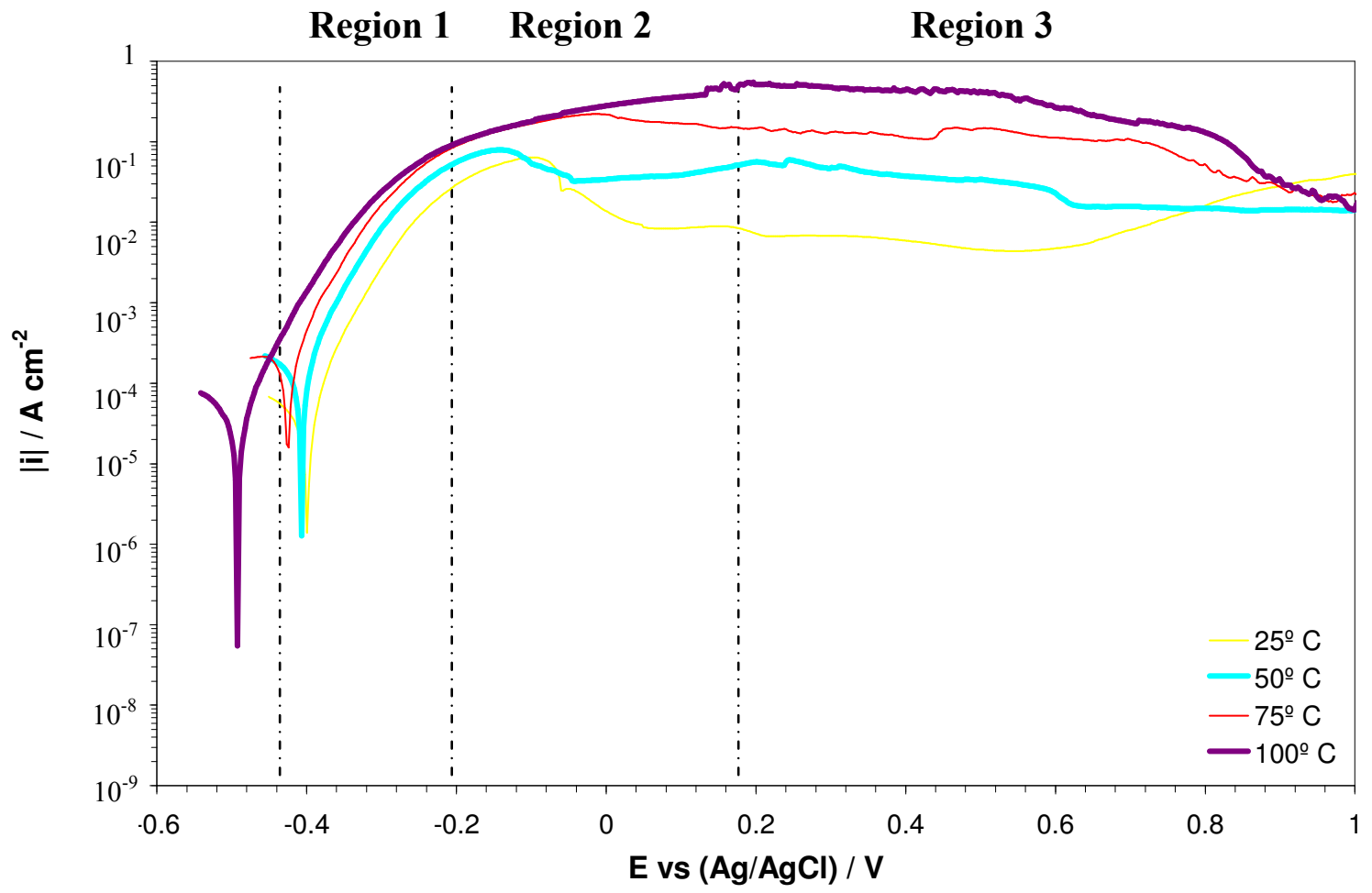


Figure 3

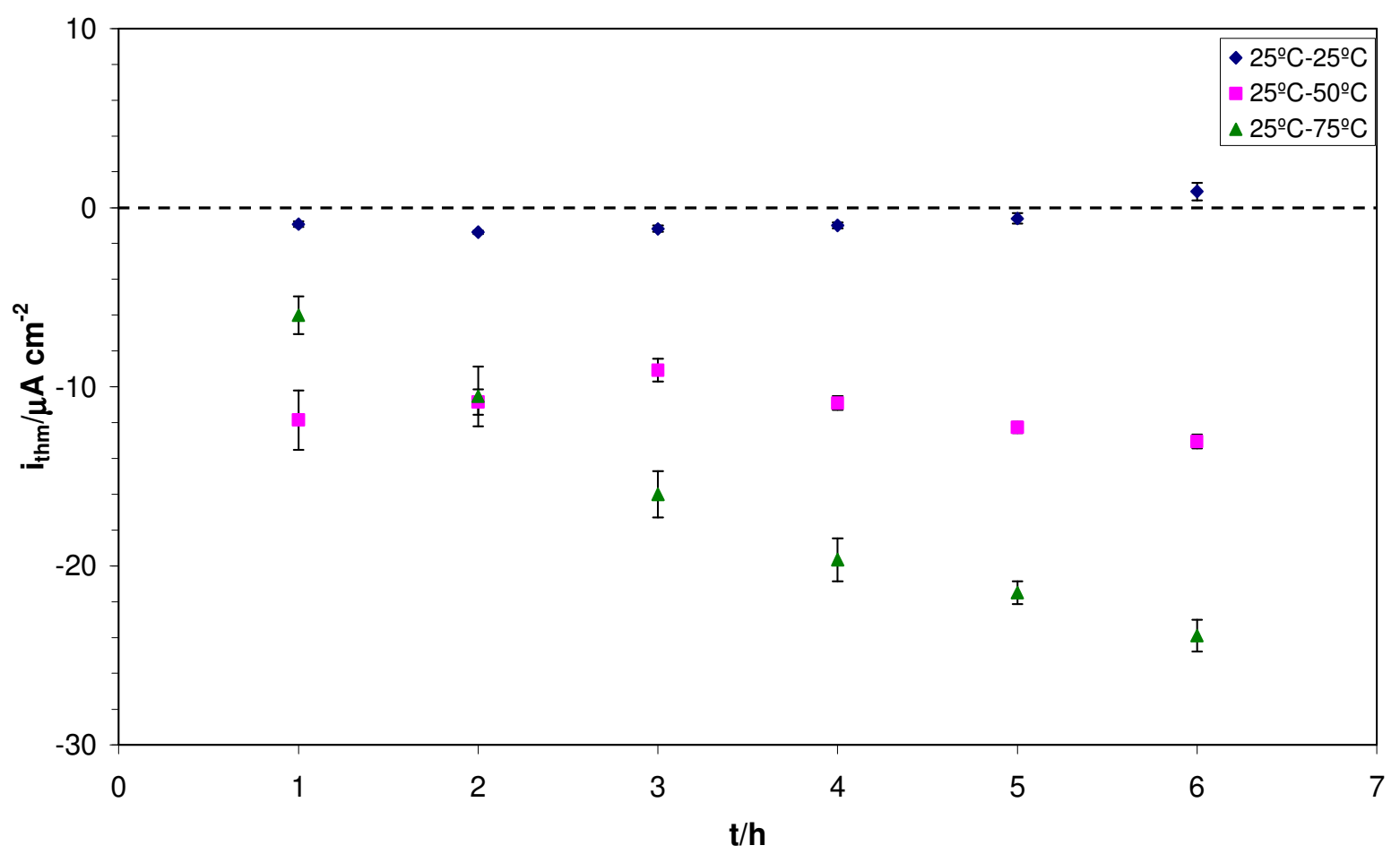

(a)

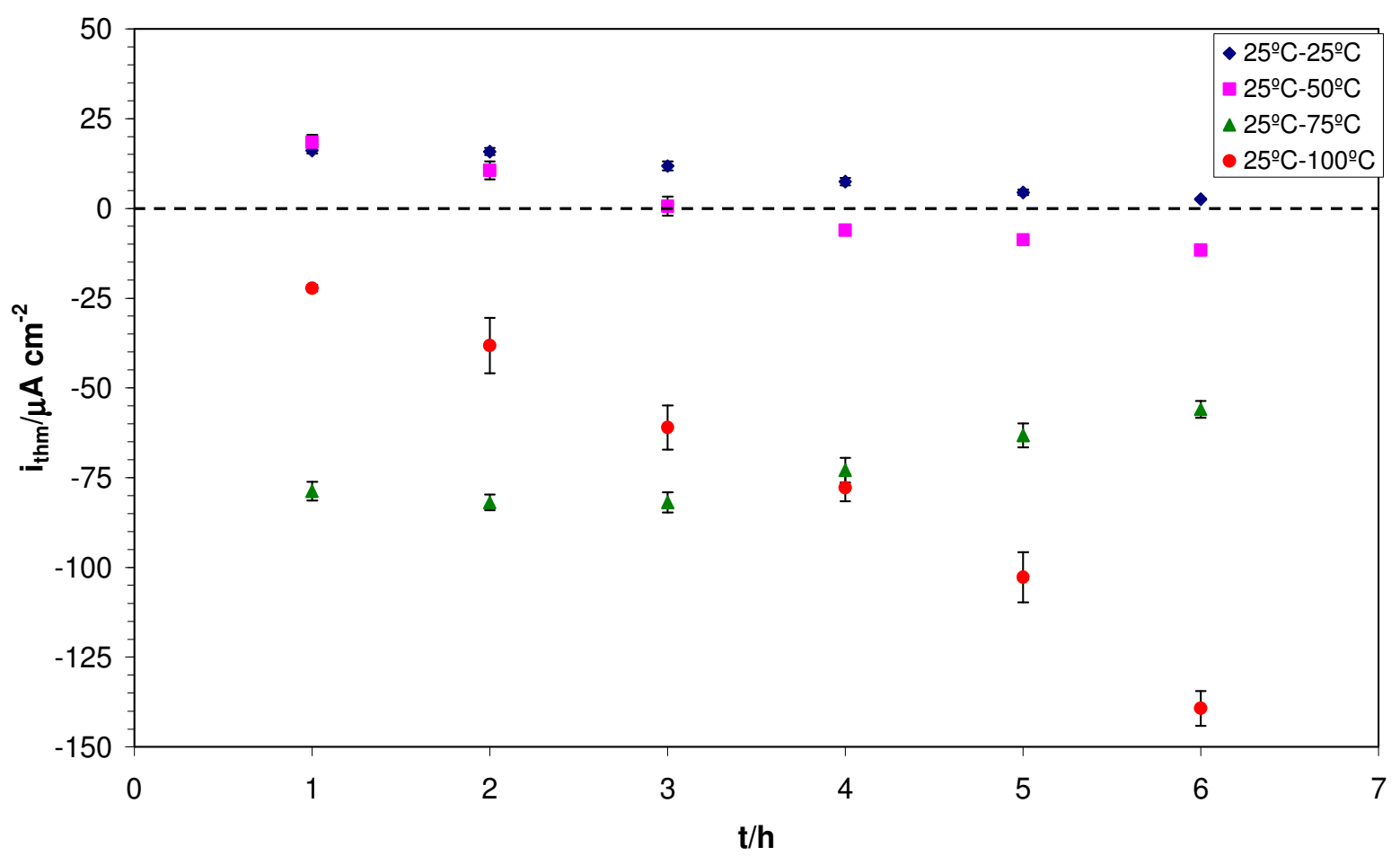

(b) 


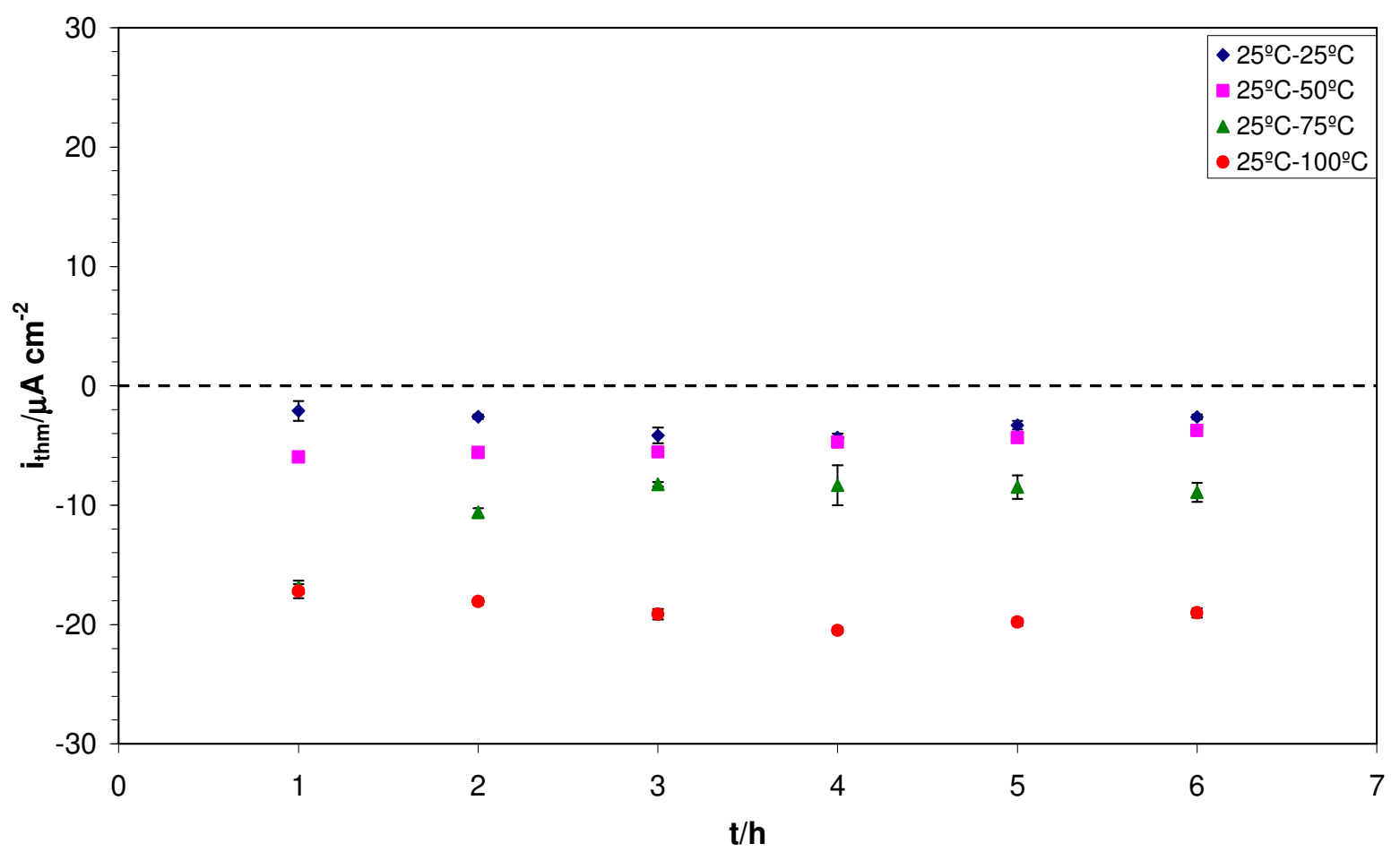

(c) 
Figure 4

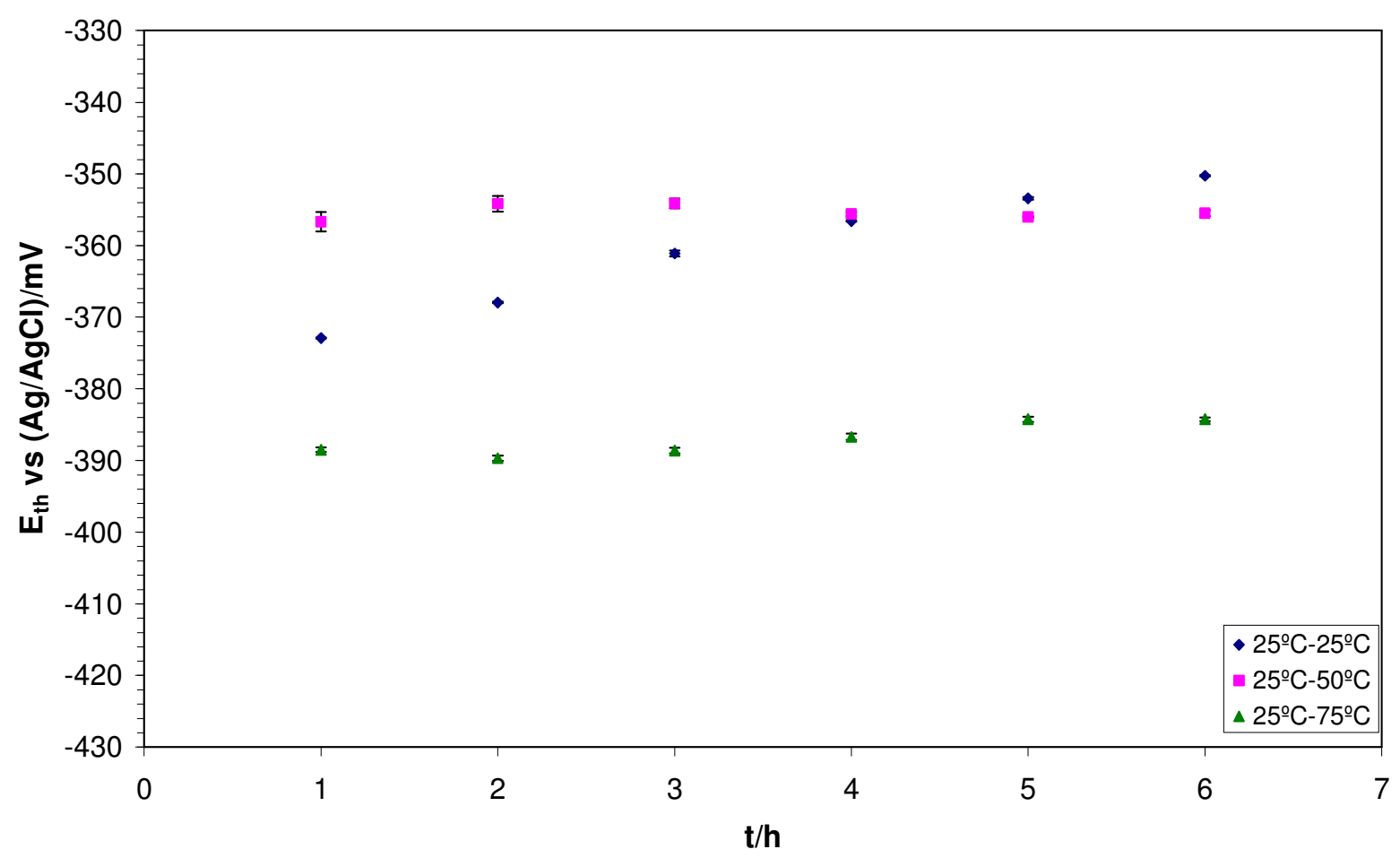

(a)

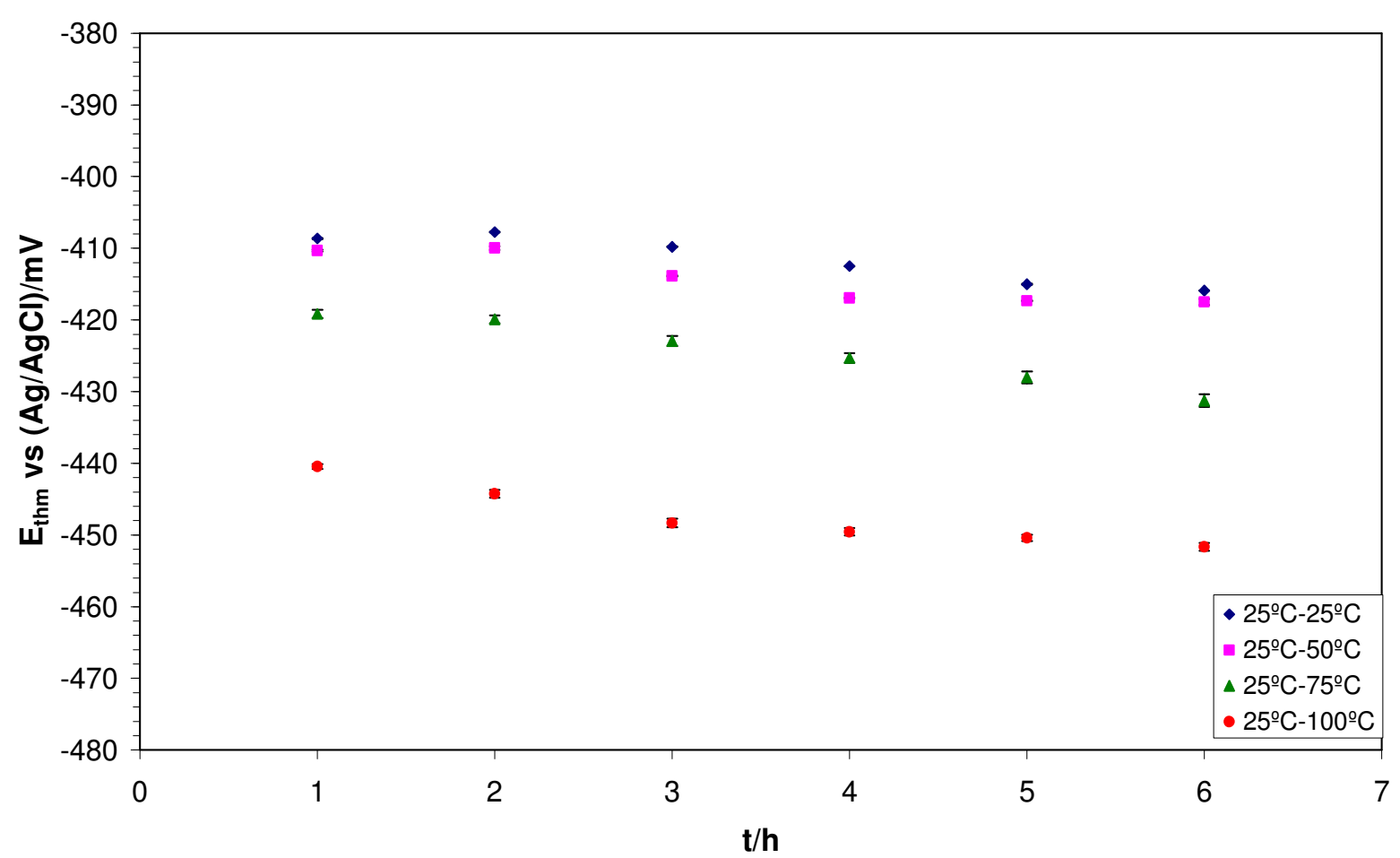

(b) 


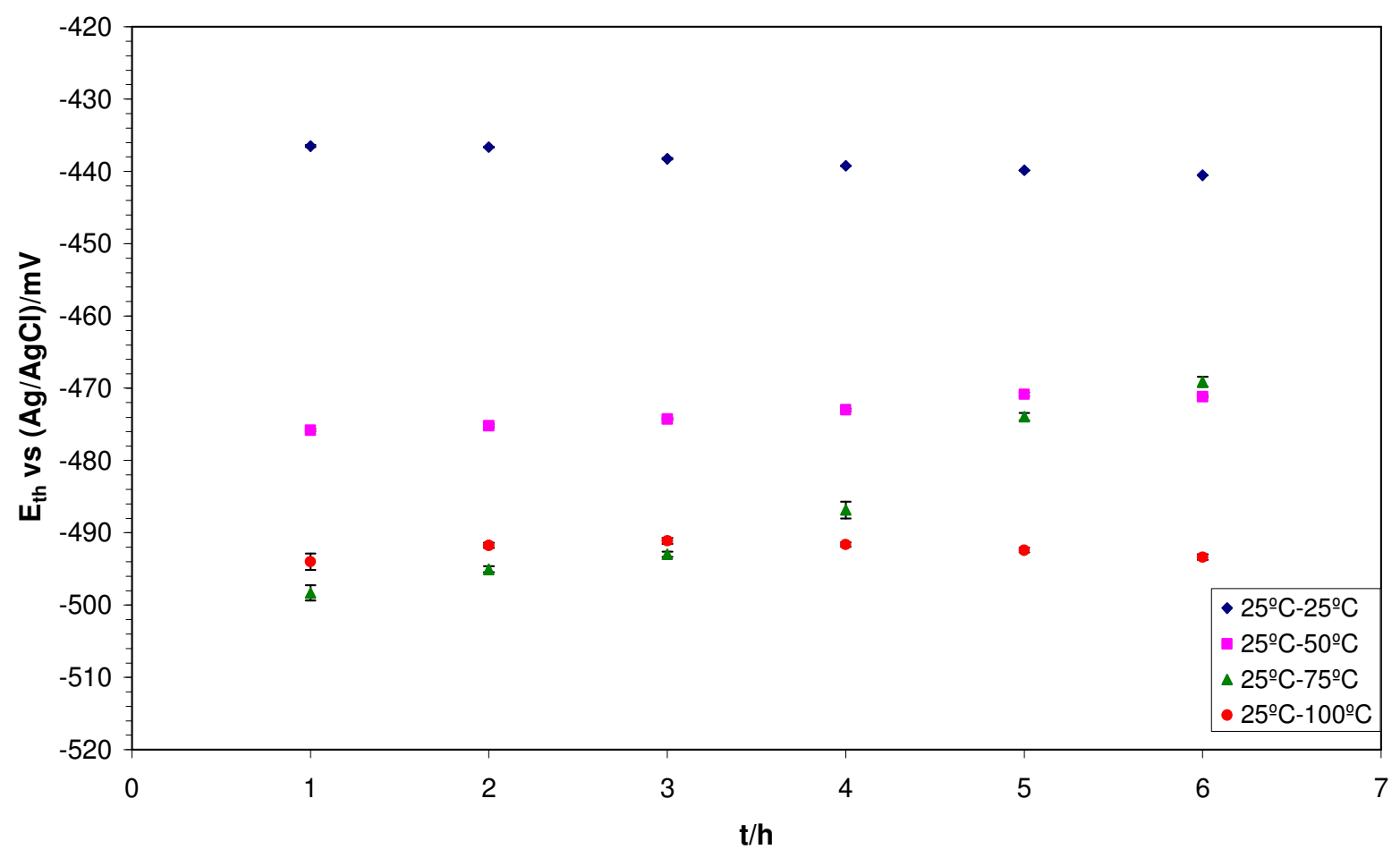

(c) 
Figure 5

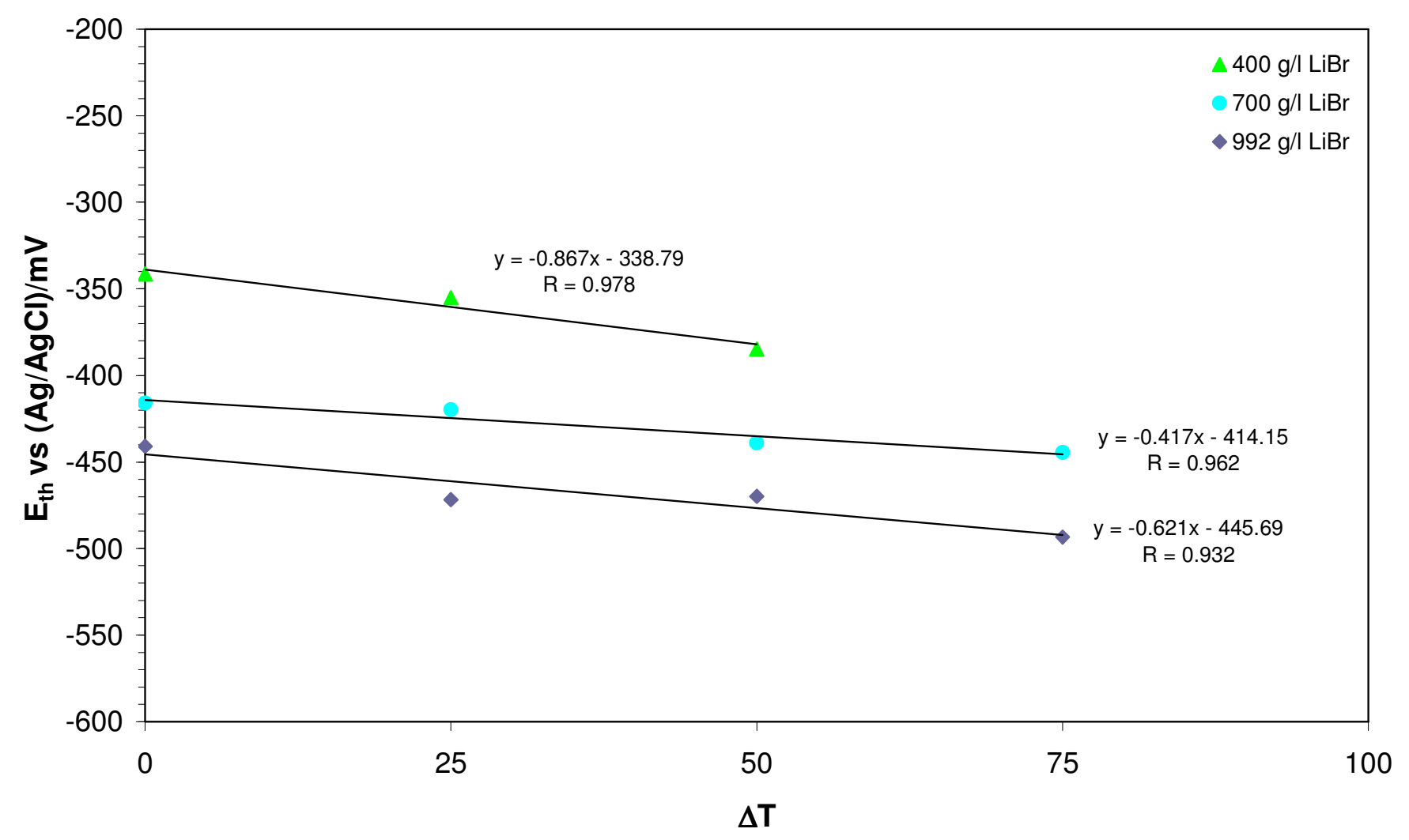



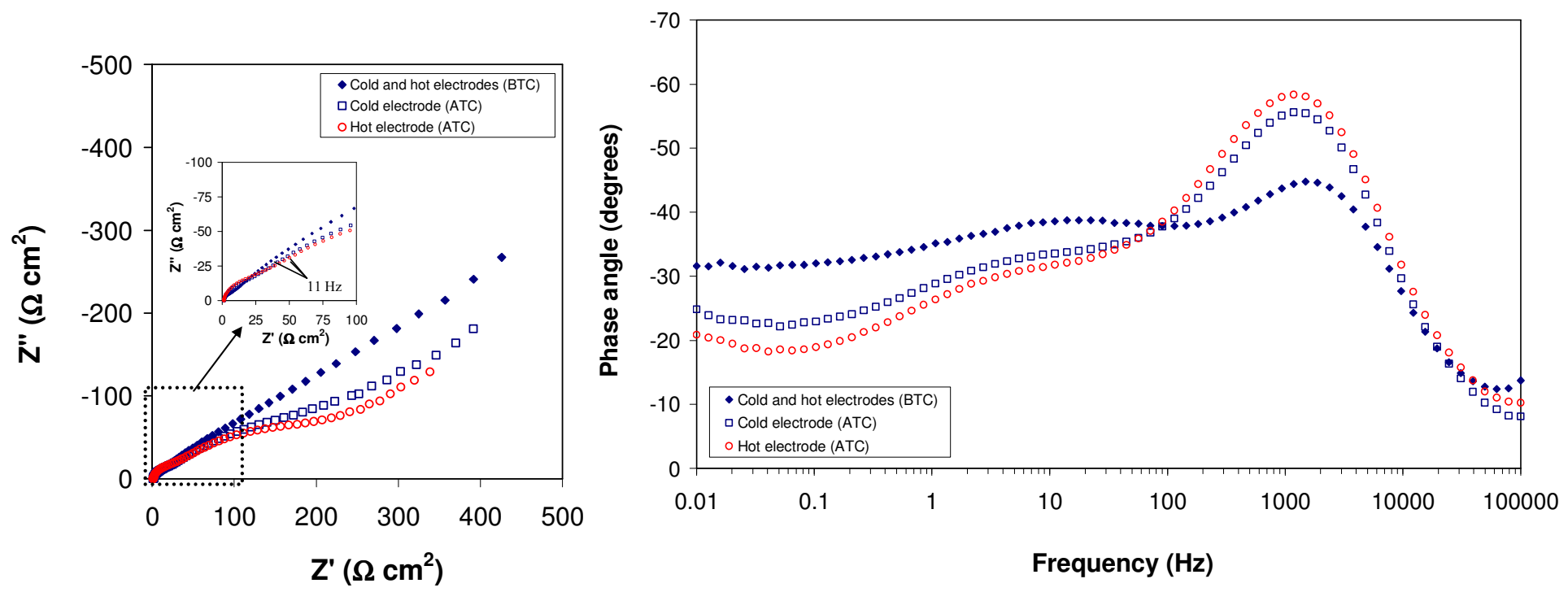

(a)
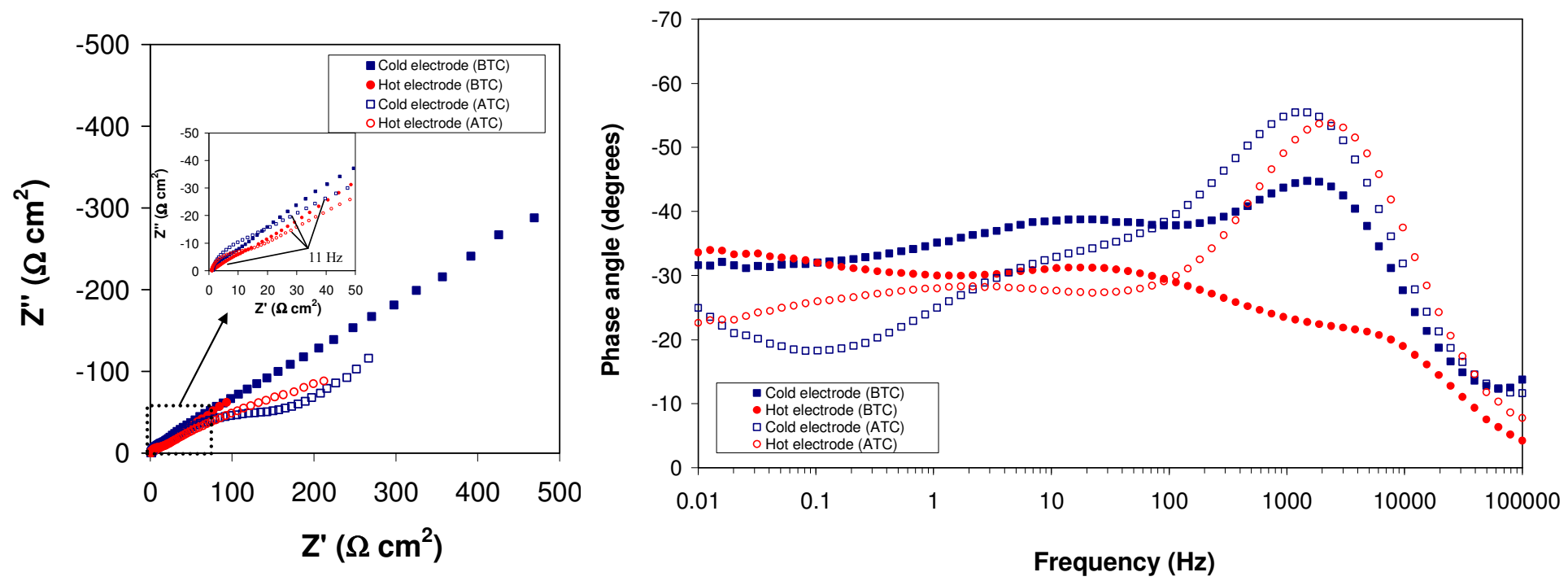

(b)
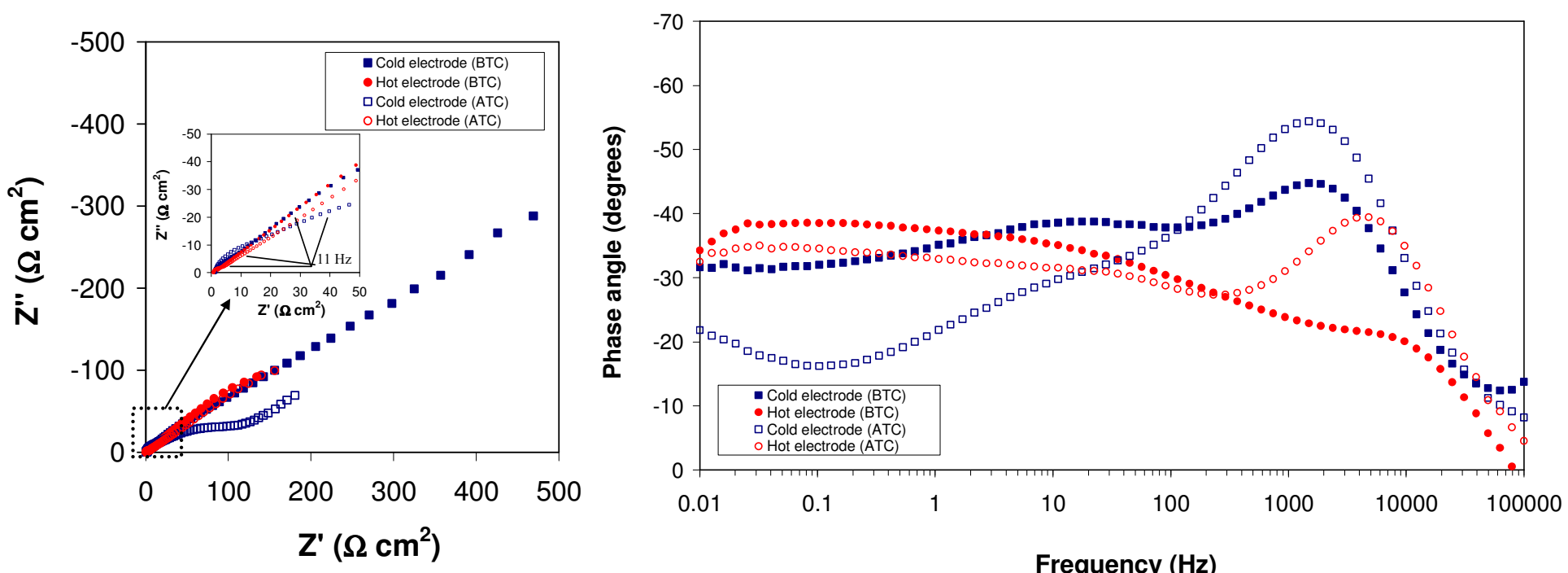

(c)

Frequency $(\mathrm{Hz})$ 

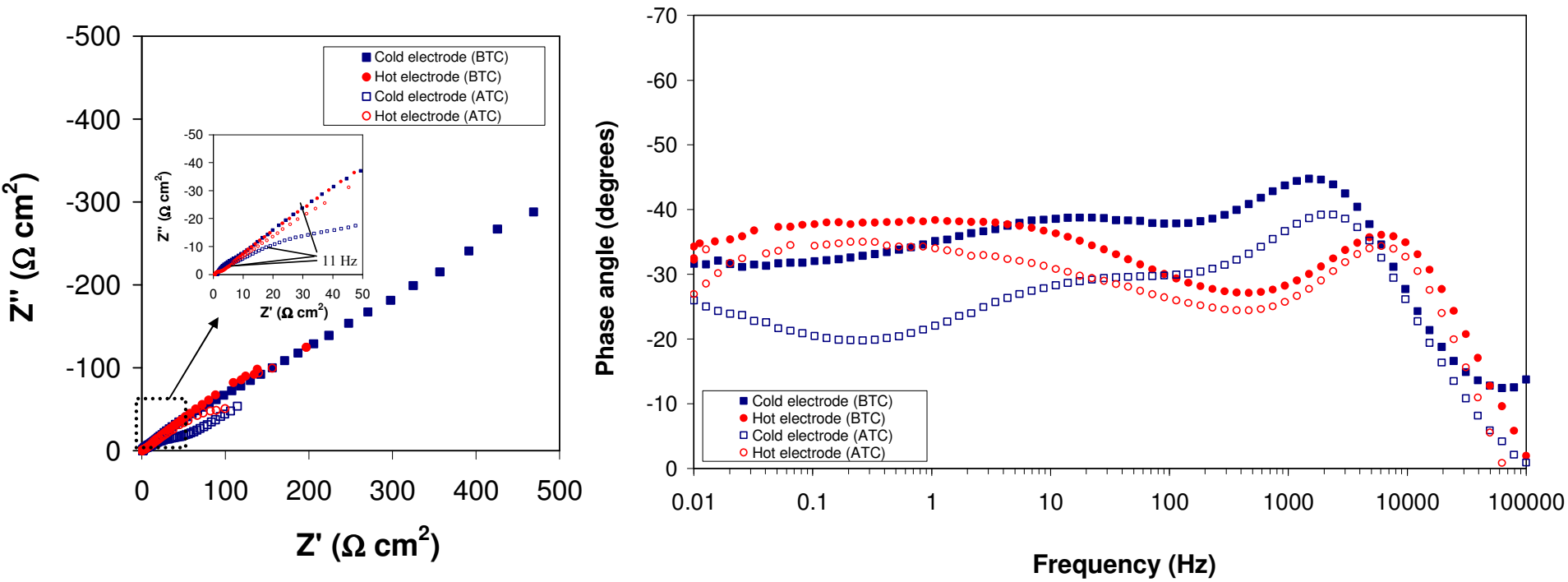

(d) 
Figure 8

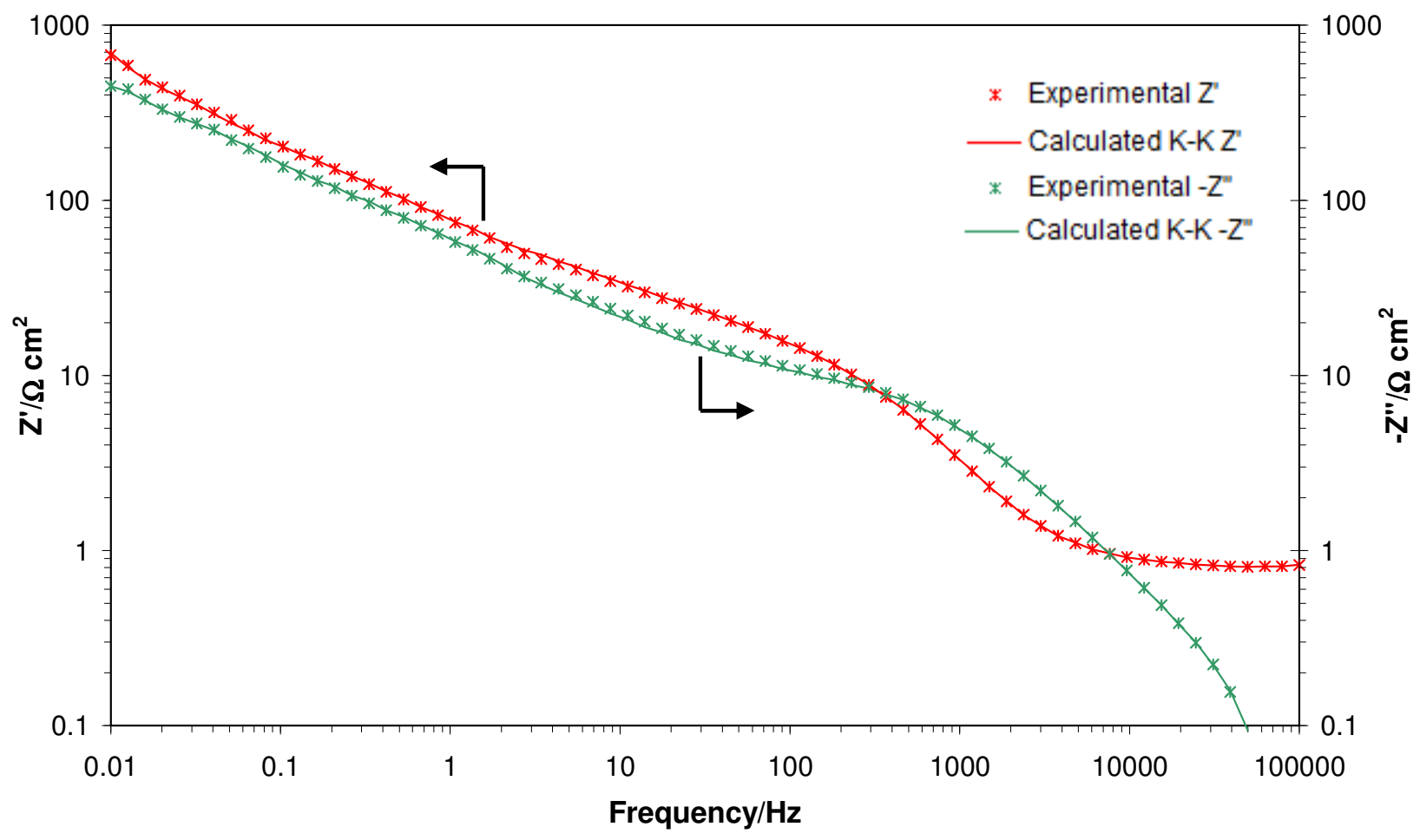

